\title{
Cardioprotective Effects of Amlodipine in the Ischemic-Reperfused Heart
}

\author{
Paul T. Hoff, BA, Yasuo Tamura, MD, and Benedict R. Lucchesi, PhD, MD
}

\begin{abstract}
Amlodipine is a dhydropyridine derivative belonging to the group of pharmacclogic calcium entry blocking agents and is characterized as having a slow onset and relatively long duration of action with minimal effects on cardiac electrophysiology and myocardial contractility.

The protective effect of amlodipine was studied in isolated blood-perfused feline hearts made globally ischemic for 60 minutes followed by reperfusion for $\mathbf{6 0}$ minutes. Ischemic-induced alterations of left ventricular developed pressure and compliance were monitored. In 11 control and 7 drugtreated hearts, amlodipine produced significant decreases in myocardial oxygen consumption (6.2 \pm 0.4 to $4.4 \pm 0.4 \mathrm{ml}$ oxygen $/ \mathrm{min} / 100 \mathrm{~g}$ ) and coronary vascular resistance, as assessed by changes in perfision pressure (120 \pm 1 to $100 \pm 4 \mathrm{~mm} \mathrm{Hg})$. Amlodiplne adminlstered before the enset of global ischemia decreased the development of ischemic contrachure as refiected by a progressive increase in resting left ventricular diastolic pressure. The retum of contractle function, 60 minutes after reperIusion, improved significantly in the amlodipinetreated group compared with controls, and there was better maimienance of the tissue concentration of $\mathrm{Na}^{+}, \mathrm{Ca}^{2+}$ and $\mathrm{K}^{+}$.
\end{abstract}

A canine model of regional myocardial ischemia (90 minutes) followed by 6 hours of reperfusion was used to assess the cardioprotective effects of amlodipine, $150 \mu \mathrm{g} / \mathrm{kg}$, administered 15 minutes before reperfusion. Infarct size, expressed as a percentage of the area at risk, was smaller in the amlodipine-treated group ( $n=10$ ) than in the control group $(n=10)(34.5 \pm 3.8 \%$ vs $45.9 \pm 2.8 \%$, $p=0.027$ ). Risk region size did not differ between groups and both groups were comparable with respect to the hemodynamic parameters of heart rate, blood pressure and rate-pressure product. Amlodipine prevented the gradual reduction in coronary blood flow observed in the control group.

From the Department of Pharmacology, The University of Michigan Medical School, Ann Arbor, Michigan. This study was supported by Grant HL-19782-10 from the Heart, Lung, and Blood Institute, National Institutes of Health, Bethesda, Maryland; and a grant from Pfizer Central Research, United Kingdom.

Address for reprints: Benedict R. Lucchesi, PhD, MD, Department of Pharmacology, M6322 Medical Science Building I, The University of Michigan Medical School, Ann Arbor, Michigan 48109-0626.
It is conchuded that amlodipine reduces myocardial ischemic injury by mechanism(s) that may involve a reduction in myocardial oxygen demand as well as by positively influencing transmembrane $\mathrm{Ca}^{2+}$ fuxes during ischemia and reperfusion.

(Am J Cardiol 1989;64101 I-116 I)

Oran alcium ion $\left(\mathrm{Ca}^{2+}\right)$ channel entry blockers have found application in the treatment of a variety of cardiovascular disorders. ${ }^{1,2}$ Amlodipine, [3-ethyl 5-methyl 2-(2 aminoethoxymethyl) 4-(2 chlorophenyl) 1,4-dihydro 6-methyl 3,5-pyridine-dicarboxylate benzene sulfonate], is a new addition to the dihydropyridine class of voltage-dependent $\mathrm{Ca}^{2+}$ channel entry blockers. In addition to possessing many of the properties of the prototype dihydropyridine, nifedipine, amlodipine displays a slow-onset and relatively long duration of action. ${ }^{3-5}$ Because of the relative selectivity of these agents for vascular smooth muscle without significant cardiac side effects, ${ }^{6,7}$ the pharmacologic profile of the dihydropyridines makes them particularly suitable for the prevention of myocardial injury in the setting of ischemia and reperfusion. ${ }^{8-10}$

Myocardial ischemia is associated with a loss of $\mathrm{Ca}^{2+}$ homeostasis. ${ }^{11-13}$ The subsequent increase in free intracellular $\mathrm{Ca}^{2+}$ is a consequence of ischemic tissue injury, ${ }^{14-16}$ and has been shown to be associated with decreased recovery of myocardial contractile function, compromised membrane integrity and a progressive decline in cellular adenosine triphosphate (ATP) stores. Previous studies in our laboratory and elsewhere have demonstrated the efficacy of diltiazem and nifedipine in protecting the myocardium against irreversible tissue injury in the setting of global or regional ischemia followed by reperfusion. ${ }^{17-19}$ Because of this favorable pharmacologic profile it was considered of interest to explore the potential of amlodipine to protect the myocardium against the development of irreversible cellular injury associated with a period of ischemia followed by reperfusion.

The study was conducted in 2 well-characterized experimental models that allowed for the induction of global myocardial ischemia (blood-perfused, feline isolated hear ${ }^{20}$ ) or regional myocardial ischemia (coronary artery occlusion, canine heart) followed by reperfusion. ${ }^{21,22}$ Pretreatment with amlodipine resulted in an improved return of function on reperfusion of the globally ischemic heart and a significant reduction in myocardial injury in response to regional myocardial ischemia followed by 


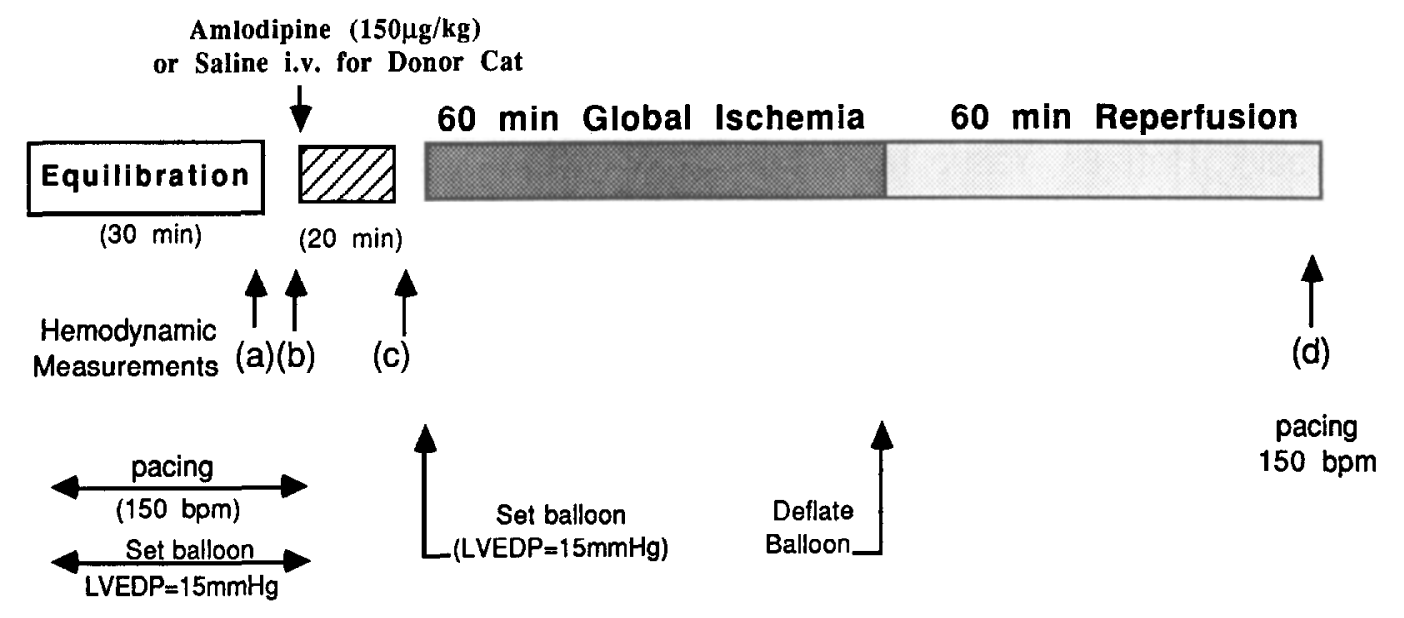

(a) Pre-Ischemic Measurements

(d) Post-Ischemic Measurements

Coronary Blood Flow (at LVEDP $=0 \mathrm{mmHg}$ ) Function \&Compliance Curves (LVEDP $=0-30 \mathrm{mmHg}$ ) Paced (150 bpm)

(b) Pre-Drug or Saline Measurements

(c) Post-Drug or Saline Measurements

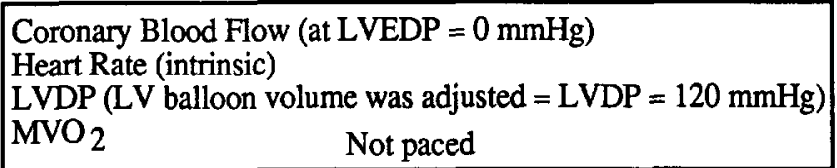

FGURE 1. Protocol for the study of ambolpine in the isolated, blood-perfused foline hoart. i.v. = intravenous; LVDP = loft ventricular developed preseure; LVEDP = left ventricular end-diastollc prescure; $\mathrm{MVO}_{2}=$ myocandiel oxysen conaumplion.

reperfusion. Thus, amlodipine may be of potential value in instances where myocardial cell viability is jeopardized by ischemia or reperfusion, or both.

\section{METHODS}

Studies in feline blood-perfused isolated heart to determine effects of ambolpine on mechanical and biochemical functional parameters after global ischemia and repertusion-experimental protocel: The experiments were performed in a model of global ischemia previously described by Vogel and Lucchesi. ${ }^{20}$ Hearts were obtained from cats $(1.5$ to $3.0 \mathrm{~kg}$ ) of either gender, anesthetized with sodium pentobarbital $(30 \mathrm{mg} / \mathrm{kg}$ intraperitoneally) and treated with the anticoagulant sodium heparin, $300 \mathrm{U} / \mathrm{kg}$ intravenously (i.v.). Blood donor cats $(3.0$ to $6.0 \mathrm{~kg}$ ) of either gender were anesthetized with Dial-Urethane $(0.7 \mathrm{ml} / \mathrm{kg}$ intraperitoneally) containing allobarbital, $100 \mathrm{~g} /$ liter; urethane, $400 \mathrm{~g}$ /liter; and monoethylurea, $400 \mathrm{~g} /$ liter. Blood donor cats were heparinized with an initial dose of heparin, $400 \mathrm{U} / \mathrm{kg}$ i.v., and subsequent hourly doses of $300 \mathrm{U} / \mathrm{kg}$. Tracheotomy of donor cats was performed and they were ventilated with room air using a Harvard respirator pump with rate and tidal volume adjusted to maintain normal arterial blood values of $\mathrm{pH}, \mathrm{pO}_{2}$ and $\mathrm{pCO}_{2}$, which were measured during the course of each experiment. Catheters were placed in the right and left femoral artery and a femoral vein of the donor cat to measure arterial blood pressure and for connection to the blood perfusion apparatus and venous return reservoir.
The heart was removed quickly from the donor cat and perfused via the aorta with arterial blood drawn from the blood donor cat with a bilateral roller pump. Aortic perfusion pressure was maintained between 75 and 90 $\mathrm{mm} \mathrm{Hg}$ by adjusting the speed of the roller pump which delivered blood from the donor cat to the isolated heart. The temperature of the blood that perfused the isolated heart was maintained at $37^{\circ} \mathrm{C}$ by passing it through a heat exchanger. Coronary venous blood was drained from the right ventricle of the isolated heart by cannulation of the pulmonary artery and was returned to the donor cat via the femoral vein as was the Thebesian drainage from the left ventricle which exited from a cannula inserted at the apex of the heart.

A saline-filled latex balloon connected to a pressure transducer was placed in the left ventricle by insertion through the left atrium and across the mitral valve. Blood that passed the aortic valve of the isolated heart and collected in the left ventricle was drained via a vent in the apex of the heart. The heart was surrounded by a glass water jacket maintained at $37^{\circ} \mathrm{C}$. The hearts were paced electrically by a pair of bipolar platinum wire electrodes attached to the right atrium. Before undergoing global ischemia, the isolated heart was allowed to equilibrate for at least 30 minutes. Heart rate and left ventricular enddiastolic pressure (LVEDP) were maintained at 150 beats/min and $15 \mathrm{~mm} \mathrm{Hg}$ (by adjustment of the intraventricular balloon volume), respectively.

After equilibration, preischemic measurements of the left ventricular mechanical function were obtained by 


\begin{tabular}{|c|c|c|c|c|c|c|c|c|c|c|c|c|}
\hline \multirow{3}{*}{$\begin{array}{l}\text { Saline } \\
\qquad(n=11)\end{array}$} & \multicolumn{2}{|c|}{$\begin{array}{l}\text { Pre Post } \\
\text { (beats/min) }\end{array}$} & \multicolumn{2}{|c|}{$\begin{array}{l}\text { Pre Post } \\
(\mathrm{mm} \mathrm{Hg})\end{array}$} & \multicolumn{2}{|c|}{$\begin{array}{l}\text { Pre Post } \\
\text { (beats/min X } \\
\mathrm{mm} \mathrm{Hg} \text { ) }\end{array}$} & \multicolumn{2}{|c|}{$\begin{array}{l}\text { Pre Post } \\
(\mathrm{mlO} / 2 / \mathrm{min} / 100 \mathrm{~g})\end{array}$} & \multicolumn{2}{|c|}{$\begin{array}{l}\text { Pre Post } \\
(\mathrm{ml} / \mathrm{min} / \mathrm{g})\end{array}$} & \multicolumn{2}{|c|}{$\begin{array}{l}\text { Pre Post } \\
(\mathrm{mm} \mathrm{Hg} / \mathrm{sec})\end{array}$} \\
\hline & 156 & 153 & 120 & 120 & 18.8 & 18.3 & 6.2 & 6.2 & 1.13 & 1.13 & 13.7 & 13.7 \\
\hline & \pm 8 & \pm 9 & \pm 1 & \pm 1 & \pm 1 & \pm 1 & \pm 0.4 & \pm 0.3 & \pm 0.04 & \pm 0.04 & \pm 0.7 & \pm 0.8 \\
\hline \multirow{2}{*}{$\begin{array}{l}\text { Amlodipine } \\
\quad(n=7)\end{array}$} & 141 & 136 & 120 & $100^{8}$ & 16.9 & $13.8^{\$}$ & 6.2 & $4.4 \S$ & 1.07 & 1.16 & 11.5 & $9.8^{\S}$ \\
\hline & \pm 8 & \pm 8 & \pm 1 & \pm 4 & \pm 1 & \pm 1 & \pm 0.4 & \pm 0.4 & \pm 0.05 & \pm 0.10 & \pm 1.2 & \pm 1.0 \\
\hline 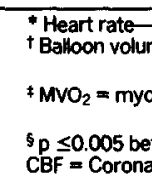 & $\begin{array}{l}\text { insic (n } \\
\text { vas adju } \\
\text { dilal oxy } \\
\text { en pre- } \\
\text { lood flo }\end{array}$ & $\begin{array}{l}\text { ced) rat } \\
\text { so that } \\
\text { onsump } \\
\text { ostinfus } \\
\text { DP }=\text { le }\end{array}$ & $\begin{array}{l}\text { I LVDP } \\
\text { calcult } \\
\text { alues } \\
\text { ntricula }\end{array}$ & $\begin{array}{l}\text { approxim } \\
\text { rom the } \\
\text { t test). } \\
\text { eloped } p\end{array}$ & $120 \mathrm{mr}$ & $\frac{\mathrm{AO}_{2}-\mathrm{VO}_{2}}{\mathrm{H}}$ & $\frac{\mid 15 \%) \mid x}{\text { art Weig }}$ & $(\mathrm{ml} / \mathrm{min})$ & & & & \\
\hline
\end{tabular}

generating function (Starling) and compliance curves. This was accomplished by measuring left ventricular developed pressure (LVDP), left ventricular $\mathrm{dP} / \mathrm{dT}$ and LVEDP on inflation of the intraventricular balloon in increments of $0.2 \mathrm{ml}$ over a range of volumes producing LVEDPs of 0 to $30 \mathrm{~mm} \mathrm{Hg}$. Isolated feline hearts were paced electrically during the pre- and postischemic measurements of mechanical function to minimize the differences in contractility due to heart rate. ${ }^{23}$ The hearts were divided randomly into 2 groups: saline- and amlodipinetreated groups. The dose of amlodipine was based on the weight of the blood donor cat. The isolated heart was exposed to either amlodipine ( $150 \mu \mathrm{g} / \mathrm{kg}$ donor cat, dissolved in $5 \mathrm{ml}$ of saline) or saline $(5 \mathrm{ml})$ and administered by infusion over a period of 5 minutes into the femoral vein of the blood donor cat (Fig. 1).

The effects of amlodipine on myocardial contractile performance and oxygen $\left(\mathrm{O}_{2}\right)$ consumption $\left(\mathrm{MVO}_{2}\right)$ were assessed under conditions described in the legend to Table I. $\mathrm{MVO}_{2}$ was determined by measuring the $\mathrm{O}_{2}$ content of arterial and venous blood samples, drawn from the aortic and pulmonary arterial cannulas, respectively. $\mathrm{O}_{2}$ content of the blood was determined with the use of a Lex- $\mathrm{O}_{2}$-Con $\mathrm{O}_{2}$ analyzer (Lexington Instruments, Waltham, Massachusetts), which was calibrated against room air and for ambient barometric and water-vapor pressures. Coronary blood flow was measured by collecting timed samples from the pulmonary arterial cannula in a graduated cylinder at $0 \mathrm{~mm} \mathrm{Hg} \mathrm{LVEDP.}$

After contractile measurements, isolated hearts were made globally ischemic for 60 minutes by turning off the roller pump delivering arterial blood to the heart. The volume of the intraventricular balloon was set so as to produce $15 \mathrm{~mm} \mathrm{Hg} \mathrm{LVEDP} \mathrm{immediately} \mathrm{before} \mathrm{the} \mathrm{in-}$ duction of global ischemic arrest of the heart. LVEDP was allowed to change spontaneously over the course of the ischemic period. When subjected to global ischemic arrest, the isolated hearts were kept normothermic $\left(37^{\circ} \mathrm{C}\right)$ by immersion in physiologic saline contained in a heated jacketed reservoir. Electrical pacing was discontinued during the ischemic period.

At the end of the 60-minute period of global ischemia, reperfusion was initiated by restoring blood flow to the isolated hearts. Postischemic perfusion was maintained for 60 minutes and the coronary blood flow was adjusted to a rate that returned perfusion pressure to preischemic levels $(75$ to $90 \mathrm{~mm} \mathrm{Hg}$ ). At the onset of reperfusion, the volume in the left ventricular balloon was decreased to 0 $\mathrm{mm} \mathrm{Hg} \mathrm{LVEDP} \mathrm{in} \mathrm{order} \mathrm{to} \mathrm{prevent} \mathrm{elevated} \mathrm{end-diastol-}$ ic pressure from impeding transmural coronary blood flow as a result of extravascular compression. ${ }^{24}$ Hearts that developed ventricular fibrillation on reperfusion were defibrillated with an injection of $0.05 \mathrm{ml}$ saturated $\mathrm{KCl}$ solution (not recirculated) into the aortic cannula immediately above the coronary ostia. Isolated hearts were not paced on restoring perfusion. Electrical pacing at the preischemic rate was maintained, however, during the assessment of contractile function in the postischemic recovery period. After 60 minutes of reperfusion, postischemic measurements of coronary blood flow and contractile function were repeated as described.

After obtaining postischemic measurements, the isolated hearts were perfused with $100 \mathrm{ml}$ Krebs solution to remove blood from the vascular bed and subsequently were removed from the perfusion apparatus. Intact hearts from the blood donor cats were excised and served as controls because they were not subjected to the damaging effects of the ischemic period, but were exposed to the same pharmacologic interventions as the isolated bloodperfused hearts. The intact hearts were weighed as were tissue samples obtained from both hearts. The myocardial samples were stored in a freezer at $-20^{\circ} \mathrm{C}$.

Tiseve water content: Samples of ischemic-reperfused and control (from blood donor cats) nonischemic myocardial tissues were blotted, weighed and dried in an oven to constant weight. Tissue water content, expressed as $\mathrm{ml} / \mathrm{g}$ dry weight was calculated from the ratio of tissue wet and dry weights.

Tiseve electrolytes: The dried tissue samples were digested and extracted with $\mathrm{HNO}_{3}$ and trichloroacetic acid and diluted with distilled water. Tissue $\mathrm{Na}^{+}$and $\mathrm{K}^{+}$ contents were determined by flame photometry (Instrumentation Laboratories, IL-143) and tissue $\mathrm{Ca}^{2+}$ content was determined by atomic absorption spectrophotometry 
90 min LCX Occlusion

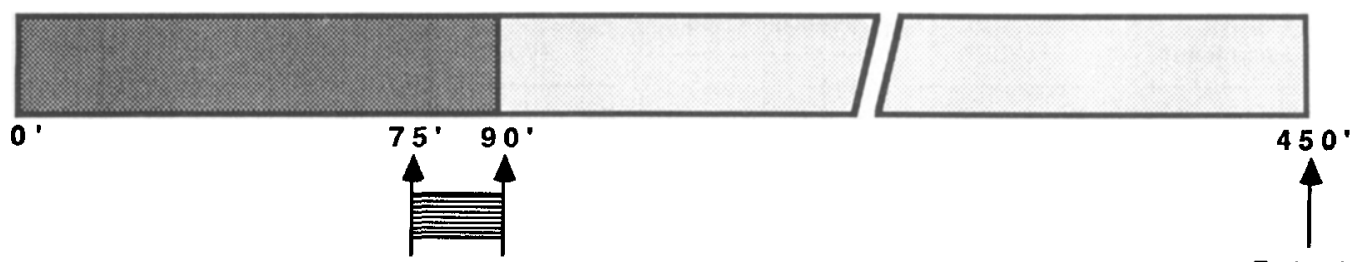

15 min i.v. infusion of Amlodipine $(150 \mu \mathrm{g} / \mathrm{kg})$ or Saline
6 Hours Reperfusion

$$
\left[\begin{array}{c}
\text { Hemodynamic Parameters } \\
\text { H.R., B.P., LCX Blood Flow, } \\
\text { Rate-Pressure Product }
\end{array}\right]
$$

Euthanize-

Heart Stain

Tissue $\mathrm{Ca}^{++}$

Histology

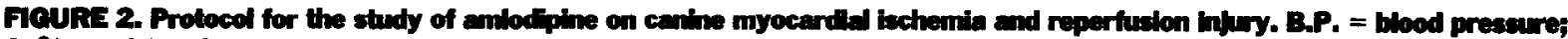

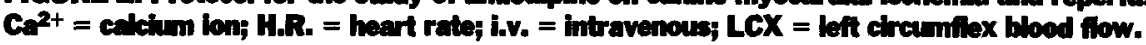

(Varian AA375, Sugarland, Texas) using $1.0 \% \mathrm{LaCl}_{3}$ (final concentration $=0.5 \%$ ) to suppress phosphate interference. Ion contents were expressed per gram of dry tissue. No attempt was made to measure and correct for the extracellular space because reperfusion after ischemia can cause gross changes in sarcolemmal permeability. ${ }^{25}$

Studies on Iimitation of ultimate infarct size in the in situ canine heart - aurgical preparation: Detailed methods have previously been published..$^{17,21,22}$ Male mongrel dogs, selected with respect to breed and weighing between 12 and $18 \mathrm{~kg}$, were anesthetized with sodium pentobarbital $(30 \mathrm{mg} / \mathrm{kg}$ i.v.). The dogs were ventilated with room air, delivered through a cuffed endotracheal tube, using a Harvard respiratory pump. Tidal volume and respiratory rate were adjusted to maintain arterial blood $\mathrm{pH}, \mathrm{pO}_{2}$ and $\mathrm{pCO}_{2}$ within physiologic limits. A thoracotomy through the left fifth intercostal space was performed and the heart was suspended in a pericardial cradle. Catheters, placed in the external jugular vein and carotid artery, were used for the administration of drugs and monitoring arterial blood pressure, respectively. Leads II, III and aVF of the electrocardiogram were monitored continuously in all experiments. The left circumflex coronary artery was isolated beneath the left atrial appendage, distal to its atrial branch and proximal to major ventricular branches. An electromagnetic flow probe connected to a digital readout meter (Carolina Instruments; King, North Carolina) was placed around the left circumflex coronary artery for continuous measurement of coronary blood flow.

Approximately 15 minutes was allowed to establish a stable hemodynamic state, after which baseline measurements of heart rate, carotid arterial blood pressure and left circumflex coronary artery blood flow were recorded. After measurements of basal coronary blood flow, a critical stenosis of the coronary artery was produced by placing an 18- or 19-gauge needle alongside the exposed artery, tying a short length of silk suture around the artery and needle, and quickly removing the needle, thereby producing a partial constriction of the vessel. The ligature was adjusted to reduce by at least $50 \%$ the reactive hyperemic response to a 10-second occlusion of the left circumflex coronary artery without altering basal coronary blood flow. The method of producing the critical stenosis effectively reduces the incidence of hemorrhagic infarction and lethal reperfusion arrhythmias. ${ }^{21}$

After reestablishment of a stable hemodynamic condition, the left circumflex coronary artery was occluded for 90 minutes using a reversible ligature made with Silastic tubing. After 90 minutes of regional ischemia, the occlusive snare was released over a period of $\mathbf{3 0}$ minutes, with the critical stenosis remaining in place. Leads II, III and aVF of the electrocardiogram, blood pressure and coronary artery blood flow were monitored and recorded on a Grass model 7 polygraph throughout the experimental procedure. The experiments were completed after 6 hours of reperfusion, after which the heart was arrested by electrically induced ventricular fibrillation and infarct size was assessed. The experimental protocol is presented in Figure 2.

Exclusion and inctusion criteria: Predetermined exclusion criteria were: (1) the presence of heart worms on final examination of the heart, (2) the failure to manifest discoloration (cyanosis) of the epicardial surface in the region of distribution of the left circumflex coronary artery after occlusion, (3) a failure to exhibit electrocardiographic signs of ischemia (ST-segment elevation) in leads II, III or aVF of the electrocardiogram, (4) a failure to develop arrhythmias on reperfusion and (5) intractable ventricular fibrillation requiring more than 3 attempts at cardioversion using low direct-current pulses $(20 \mathrm{~J})$ applied directly to the surface of the heart. Antiarrhythmic drugs for the prevention of ventricular fibrillation were not used in these experiments because of recent reports suggesting that agents such as lidocaine reduce infarct size. 26

Administration of amlodipine and saline: The dogs were assigned randomly to receive either amlodipine (150 $\mu \mathrm{g} / \mathrm{kg}$, dissolved in $20 \mathrm{ml}$ of $0.9 \%$ solution of sodium 
chloride) or $0.9 \%$ sodium chloride solution $(20 \mathrm{ml})$. Treatments were administered over a period of 5 minutes and were given 15 minutes before the onset of reperfusion (75 minutes after initiation of regional myocardial ischemia).

Determination of myocardial infarct size and area at risk: The dogs were killed 6 hours after reperfusion by the electrical induction of ventricular fibrillation $(60 \mathrm{~Hz}, 5 \mathrm{~V}$, 1-ms pulse duration applied to the surface of the heart). The hearts were excised and rinsed with warm $0.9 \%$ sodium chloride solution, weighed and attached to a perfusion apparatus. Histochemical determination of the anatomic area at risk and the zone of infarction was accomplished with an ex vivo dual perfusion technique. $21,22,27$ The left circumflex coronary artery was cannulated at the point of previous occlusion and perfused with $4 \%$ triphenyl tetrazolium chloride (TTC) in 20-mM potassium phosphate buffer $\left(\mathrm{pH} 7.4,37^{\circ} \mathrm{C}\right)$, while the aorta was perfused retrogradely with $0.25 \%$ Evans blue dye. The solutions were infused simultaneously for 5 minutes under a constant pressure of $100 \mathrm{~mm} \mathrm{Hg}$ with the heart suspended in a water bath $\left(37^{\circ} \mathrm{C}\right)$. Differential perfusion of the circumflex artery and remaining vasculature under these conditions delineates the anatomic area at risk, as well as infarcted myocardium, based on the ability of dehydrogenase enzymes present in viable myocardium to react with TTC. With this histochemical technique, myocardium that is not part of the area at risk is stained dark blue. Within the boundaries of the ared at risk, normal tissue is colored brick red by the formazan precipitate resulting from enzymatic reduction of TTC, while infarcted myocardium appears pale yellow. The heart was cut transversely into $1-\mathrm{cm}$-thick sections, revealing 3 clearly defined areas (normal myocardium in the nonrisk region, normal myocardium in the risk region and infarcted myocardium in the risk region) of the left ventricle as defined by the histochemical procedure. The fidelity of the TTC staining method has been confirmed previously. ${ }^{28,29}$ After weighing each left ventricular section, the outline of the 3 areas of both sides of each section were traced onto clear plastic overlays for subsequent quantification of the area at risk and the infarcted zone by planimetry using an Apple Graphics Tablet and Apple IIe computer. A custom-made software program was used to calculate the masses of the infarct zone and the area at risk from the planimetered areas and the weights of each section. Previous studies demonstrated that there is an excellent correlation between infarct size derived by the planimetric method and the direct gravimetric measurement. ${ }^{22}$ The method for the determination of myocardial infarct size is illustrated in Figure 3. The infarcted mass is expressed as a percent of the area at risk, and the area at risk is expressed as a percent of the left ventricle.

Tissue calcium content measurements: Portions of myocardial tissue, dissected from the 3 areas of the left ventricle (normal myocardium in the nonrisk region, normal myocardium in the risk region and infarcted myocardium in the risk region), were oven-dried to constant weight and digested in nitric acid. The tissue $\mathrm{Ca}^{2+}$ content of acid digests, diluted in lanthanum $\left(\mathrm{LaCl}_{3}\right.$; final

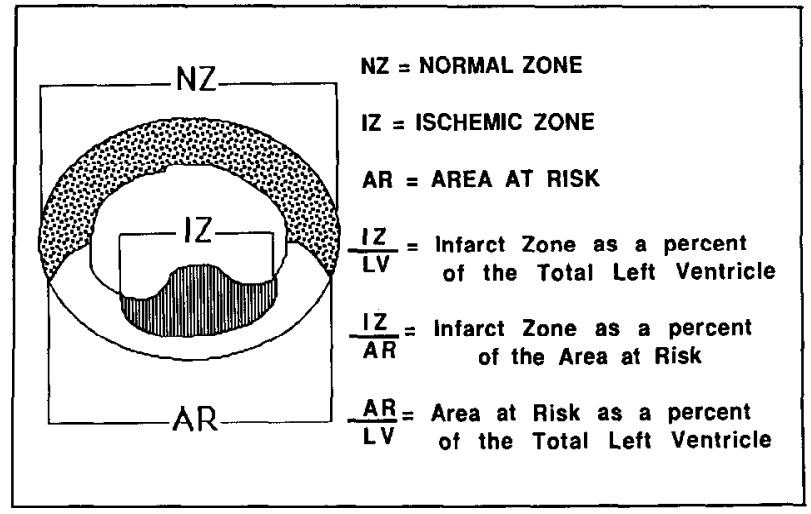

FIGURE 3. Representation of histochemical method used to quantitate infareted zone (IZ), area at risk (AR) and normal noninfarcted zone (NZ). (See text for details.)

concentration $=0.5 \%$, was measured by atomic absorption spectrophotometry (Varian AA375, Sugarland, Texas). Serial dilutions of $\mathrm{CaCO}_{3}$ standard solution, containing identical amounts of nitric acid and $\mathrm{LaCl}_{3}$, were used to construct a standard curve.

Statistical analysis: All data are reported as mean \pm 1.0 standard error of the mean. Differences between the mean values of treated and untreated groups were compared using Student $t$ test for unpaired data. Differences between values within groups were tested for statistical significance using the paired $t$ test. Differences at the $\mathrm{p}$ $<0.05$ level were considered statistically significant. Multiple comparison analysis involving more than 2 groups were performed with analysis of variance.

\section{RESULTS}

Effects of amlodipine on global ischemia-reperfusion injury in blood-perfused feline isolated heart! In all, 42 cats ( 21 donor cats and 21 cats for isolated hearts) in 21 experiments were used for this series of the study. Three experiments (6 cats) were excluded because of an inability to maintain stable hemodynamic conditions associated with metabolic acidosis of the donor cats. Thus, 36 cats (18 donor cats and 18 cats for isolated hearts) in 18 experiments initially entered the protocol. The study groups consisted of 11 control (placebo-treated) and 7 amlodipine-treated hearts.

Changes in arterial blood pressure in donor cats after administration of amlodipine: The changes in systolic, diastolic and mean arterial blood pressure in the blood donor cats after amlodipine or sodium chloride infusion are shown in Figure 4. Systolic blood pressure decreased from $125 \pm 14$ to $115 \pm 12 \mathrm{~mm} \mathrm{Hg}(\mathrm{p}<0.05) 20$ minutes after the intravenous administration of amlodipine to the blood donor cat. The administration of the diluent to the control group was not associated with any change in the blood pressure of the blood donor cat.

Effects of amlodipine on monischemic, blood-perfused feline heart: The changes in left ventricular contractile function, $\mathrm{MVO}_{2}$ and coronary blood flow after infusion with amlodipine or placebo are listed in Table I. The rate of the perfusion pump providing flow to the coronary arteries of the isolated hearts was not changed 


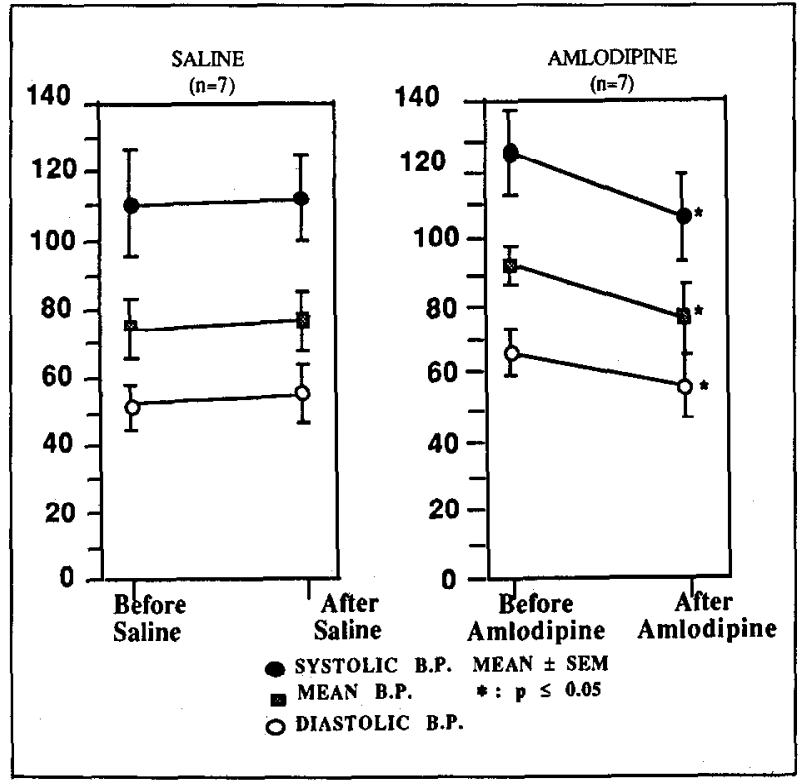

FTCURE 4. Change in arterial blood presaire (B.P.) of blood donor cats before and $\mathbf{2 0}$ minutes after treatment with elther sallie or andodpine, SIM = standard error of the mean.

until measurements after administration of the drug or placebo were obtained. Amlodipine exerted a negative inotropic effect and caused a commensurate decline of $\mathrm{MVO}_{2}$ (and rate-pressure product). The intrinsic heart rate decreased, but not significantly. Coronary vascular resistance decreased, necessitating an increase in the output of the coronary artery perfusion pump so as to return the coronary perfusion pressure to the predrug value. The increase in coronary blood flow was $8 \%(1.07 \pm 0.05$ to $1.16 \pm 0.10 \mathrm{ml} / \mathrm{min} / \mathrm{g}$ ) greater than that of the control flow before the administration of amlodipine. The change in coronary resistance, however, did not differ significantly from control.
Administration of amlodipine was associated with significant decreases in LVDP $(120 \pm 1$ to $100 \pm 4 \mathrm{~mm} \mathrm{Hg})$, which was reflected in a decrease in $\mathrm{MVO}_{2}(6.2 \pm 0.4$ to $4.4 \pm 0.4 \mathrm{ml} \mathrm{O} / \mathrm{min} / 100 \mathrm{~g}$ ) as well as a decrease in left ventricular $\mathrm{dP} / \mathrm{dtmax}$ and rate-pressure product. Thus, amlodipine $(150 \mu \mathrm{g} / \mathrm{kg})$ administered to the blood donor cat produced a negative inotropic effect in the bloodperfused isolated heart, which reflects an overall decrease in myocardial contractile function and a subsequent reduction in $\mathrm{MVO}_{2}$. The data for each of the recorded and derived parameters are presented in Table I.

Reeting left ventricular pressure changes during global ischemia: The interruption of coronary perfusion and the induction of global myocardial ischemia induced a rapid decline in LVDP. During the period of ischemic arrest, the resting left ventricular pressure (which would correspond to left ventricular diastolic pressure in the beating heart) began to increase progressively starting 20 minutes after the onset of global ischemia. After $60 \mathrm{~min}$ utes of global ischemic arrest, the resting left ventricular pressure had increased from an initial preset value of 15 $\mathrm{mm} \mathrm{Hg}$ to a mean value of $77 \pm 8 \mathrm{~mm} \mathrm{Hg}$ in the salinetreated hearts. In contrast, amlodipine pretreatment slowed the time course of the rate of increase of resting left ventricular diastolic pressure, and at the end of 60 minutes the resting left ventricular diastolic pressure was $33 \pm 6 \mathrm{~mm} \mathrm{Hg}(\mathrm{p}<0.05)$. Data are summarized in Figure 5.

Therefore, amlodipine administered before the onset of global ischemia significantly decreased the extent of development of ischemic contracture as reflected in a progressive increase in the resting LVEDP at each time point between 20 and 60 minutes of global ischemic arrest of the feline isolated heart.

Electrical activity: At the onset of ischemia, there was a rapid dissociation between contractile and electrical activity in the isolated hearts. While active pressure de-

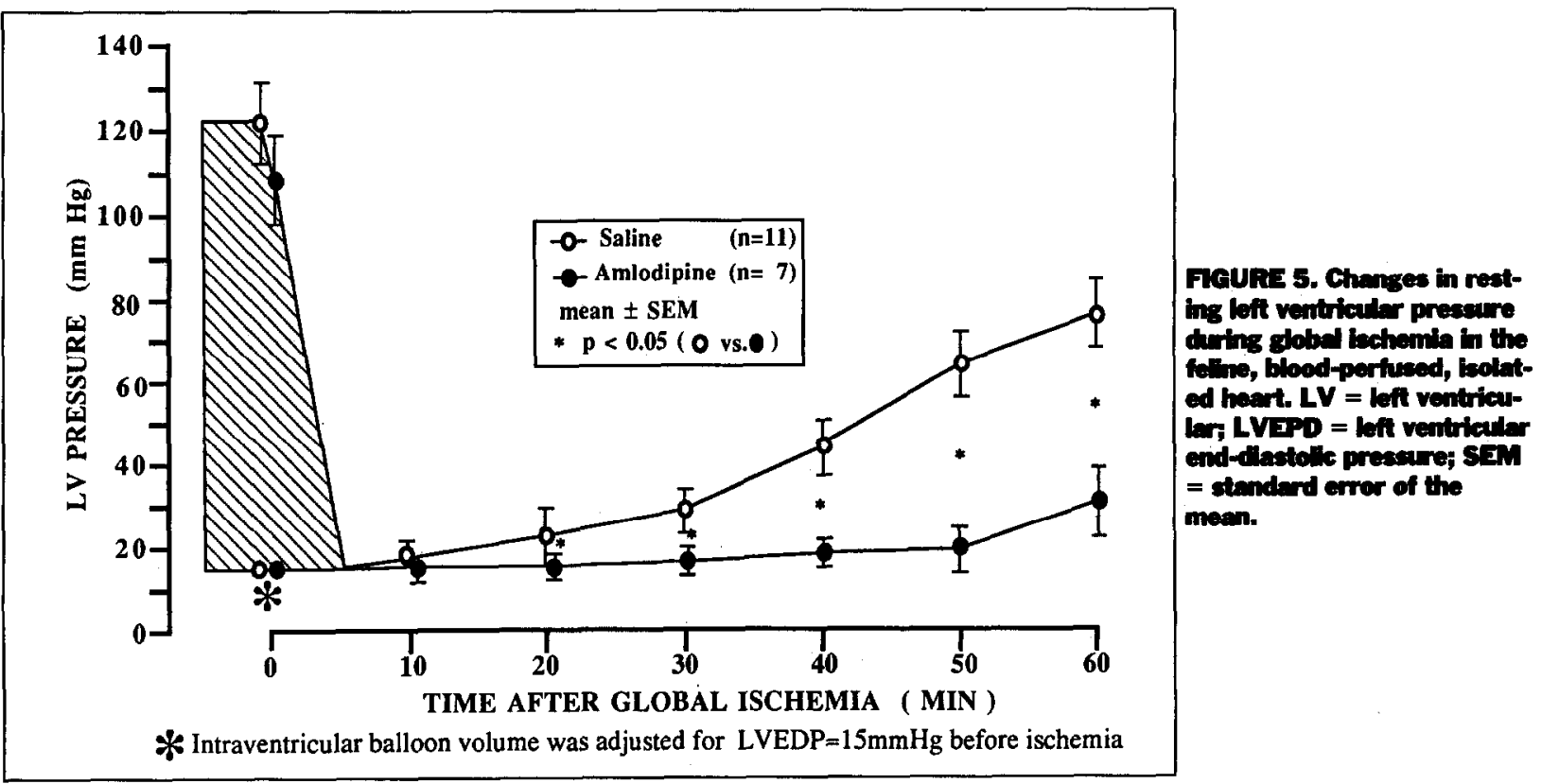




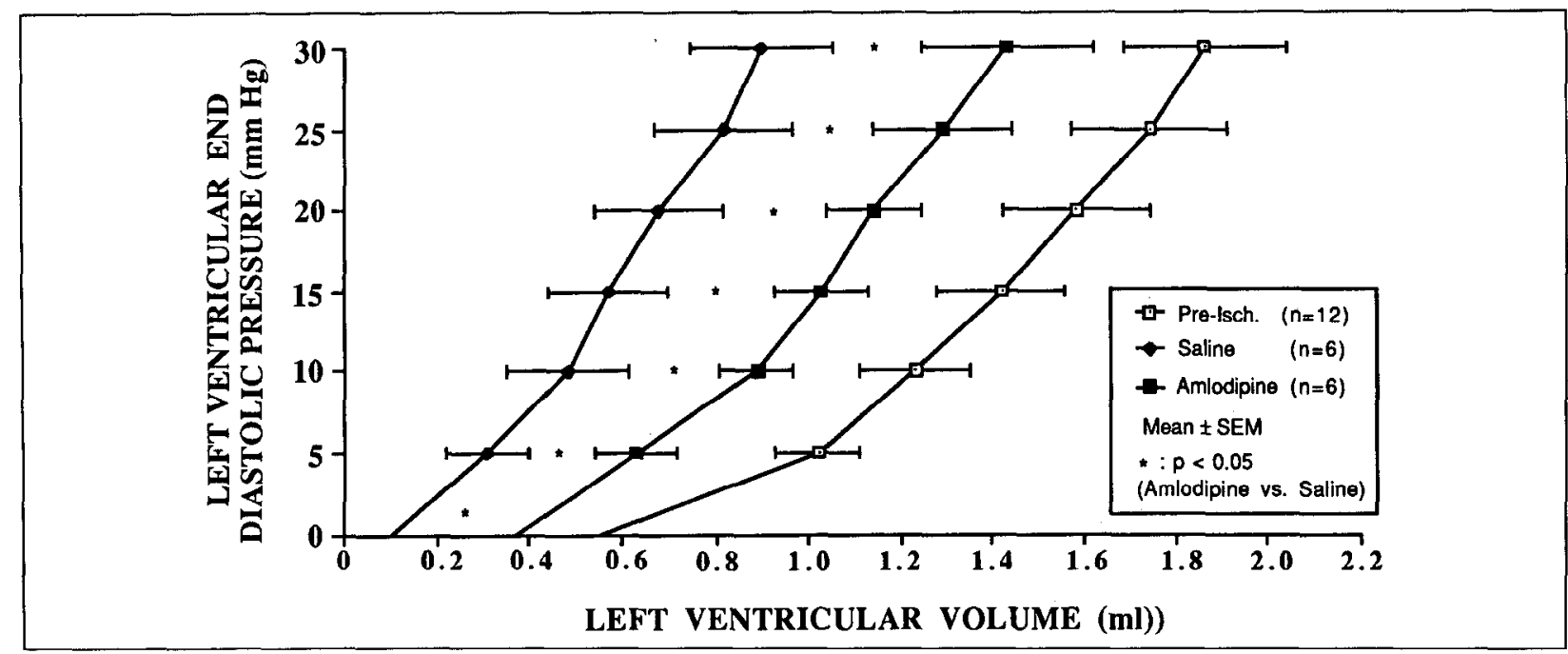

FGURE 6. Left ventricular complance of the blood-perfused, isolated felline heart. Pre-isch = pre-tachemia; SEM = standard error of the mean.

velopment ceased within 60 seconds after termination of coronary artery perfusion, electrical activity continued for several minutes. Heart rate slowed gradually and changed from a sinoatrial rhythm to one which was ventricular in origin. Ventricular fibrillation did not occur in any heart during the ischemic period, but all hearts fibrillated immediately on reperfusion. In the saline-treated group of hearts, 6 of 11 hearts reverted spontaneously to sinus rhythm, while 6 of 7 amlodipine-treated hearts spontaneously returned to normal sinus rhythm after reperfusion. The percentage of recovery was greater in amlodipine-treated hearts, although the difference between the 2 groups with respect to the spontaneous return to normal sinus rhythm was not statistically significant (54.5\% in the saline-treated group, $85.7 \%$ in the amlodipine-treated group [difference not significant; $p=N S$ ] by Fisher exact test).

Ischemia/repertusion-induced changes of left ventricudar contractile function and compllance: Changes in left ventricular compliance resulting from 60 minutes of ischemia followed by 60 minutes of reperfusion are shown in Figure 6. There was no difference between the 2 groups in the weight of the isolated hearts (saline-treated group $=12.0 \pm 0.7 \mathrm{~g}$, amlodipine-treated group $=12.6 \pm 0.7 \mathrm{~g}$; $p=N S)$. There was a significant decrease in compliance (preischemic vs 1-hour reperfusion) in both the salineand amlodipine-treated groups after ischemia and reperfusion. In the saline-treated group, all values were shifted to the left, compared with the corresponding points on the preischemic curve indicating a decrease in left ventricular compliance. The amlodipine-treated group also was characterized by a leftward shift in the ventricular compliance curve, but of a lesser magnitude at each value of left ventricular volume compared with the changes observed in the saline-treated control group. Amlodipine pretreatment resulted in a significant shift in the ventricular compliance curve toward the right compared with changes in the saline-treated group.

Ventricular function curves for the 2 groups of isolat- ed hearts are shown in Figures 7 and 8 . Sixty minutes of global ischemia plus reperfusion resulted in a decrease in LVDP compared with the preischemic control values in the saline-treated group (LVDP, $-43.5 \pm 1.3 \%$ of preischemic value). Pretreatment with amlodipine attenuated the deterioration in ventricular performance on reperfusion at each point on the left ventricular function curves. Amlodipine-treated hearts showed less of a decline in LVDP $(-20.5 \pm 0.9 \%)$ as a result of 60 minutes of ischemia and reperfusion (Fig. 7). Amlodipine also attenuated the decrease in left ventricular $\mathrm{dP} / \mathrm{dtmax}$ compared with saline-treated ischemic hearts (Fig. 8). As noted previously with respect to ventricular function, amlodipine, despite its own intrinsic negative inotropic effect, provides protection against the depression in myocardial contractility that results in the control hearts after a period of global ischemia followed by reperfusion.

Coronary blood flow: The values obtained for the measurements of coronary blood flow, before and after ischemia reperfusion, are shown in Figure 9. Coronary blood flow was measured while the hearts were paced electrically at a rate of 150 beats/min, with LVEDP set at $0 \mathrm{~mm} \mathrm{Hg}$. The values for coronary blood flow were normalized for heart weight and expressed in $\mathrm{ml} / \mathrm{min} / \mathrm{g}$ weight. Isolated hearts had a mean preischemic coronary blood flow of $1.20 \pm 0.05 \mathrm{ml} / \mathrm{min} / \mathrm{g}$ for the control group and $1.10 \pm 0.07 \mathrm{ml} / \mathrm{min} / \mathrm{g}$ for the amlodipine group $(\mathrm{p}=$ NS). Coronary blood flow increased to $1.67 \pm 0.20 \mathrm{ml} /$ $\mathrm{min} / \mathrm{g}(+30 \%$ of preischemic value) after 60 minutes of ischemia followed by 60 minutes of reperfusion in the saline-treated hearts $(p=0.021)$. In the amlodipinetreated group there was a further decrease in coronary vascular resistance so that coronary blood flow was $2.5 \pm$ $0.33 \mathrm{ml} / \mathrm{min} / \mathrm{g}(+127 \%)$ after ischemia plus reperfusion. Although there was a marked increase in coronary flow in amlodipine-treated hearts, when compared with the saline-treated group, the overall increase did not achieve statistical significance ( $\mathrm{p}=0.057$; unpaired $t$ test).

Tisave analysis: Values for water and electrolyte con- 


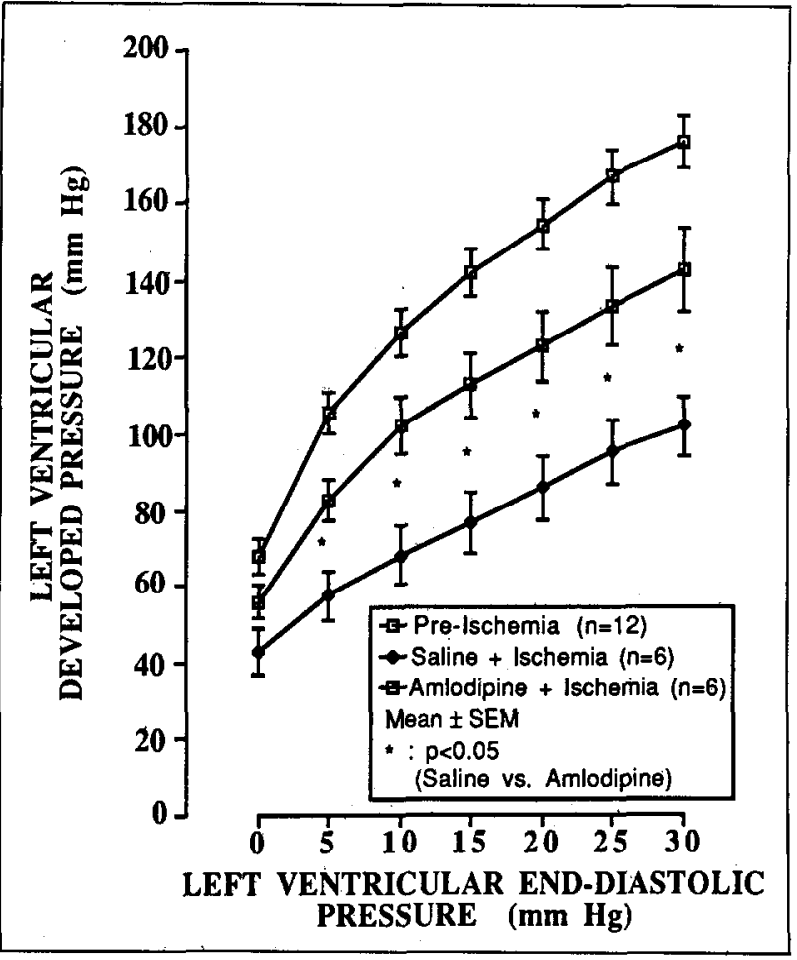

FICURE 7. Ventriarler function curves of the follne isolated, blood-perfused heart. SIM = standard error of the meen.

tents in myocardial tissue are presented in Table II. The hearts from blood donor cats served as nonischemic controls. Previous studies from this laboratory 20.30 demonstrated that the isolated blood-perfused, nonischemic control hearts did not differ from the hearts of the blood donor cats with respect to tissue contents of water, sodium, potassium or calcium. The blood-perfused isolated heart maintains its ability to control water and electrolyte composition. Any changes in water and electrolyte composition of the isolated heart could be attributed directly to the applied interventions and not to the fact that the heart had been isolated and perfused for an extended period. In both the saline- and amlodipine-treated ischemic/reperfused hearts there was a significant increase in water content, indicating edema formation. The difference between the 2 groups was not significant. Tissue potassium content decreased in both groups of ischemic hearts compared with normal hearts from the blood donor cats. Treatment with amlodipine attenuated the loss of potassium. Tissue calcium content increased in both groups as a result of ischemia plus reperfusion, and the calcium content in amlodipine-treated ischemic hearts was less than that in the saline-treated hearts. Thus, from the standpoint of electrolyte composition of the reperfused heart, amlodipine resulted in significant reductions in the loss of intracellular potassium and reduced the amount of calcium that accumulated during the period of reperfusion. The latter observation would be consistent with the finding that amlodipine preserved both systolic and diastolic functions of the reperfused heart.

Effects of ambodipine on extent of ultimate infaret she resulting from temporary coronary occhusion and repertusion in canine hearts: In all, 27 dogs (13 amlodi-

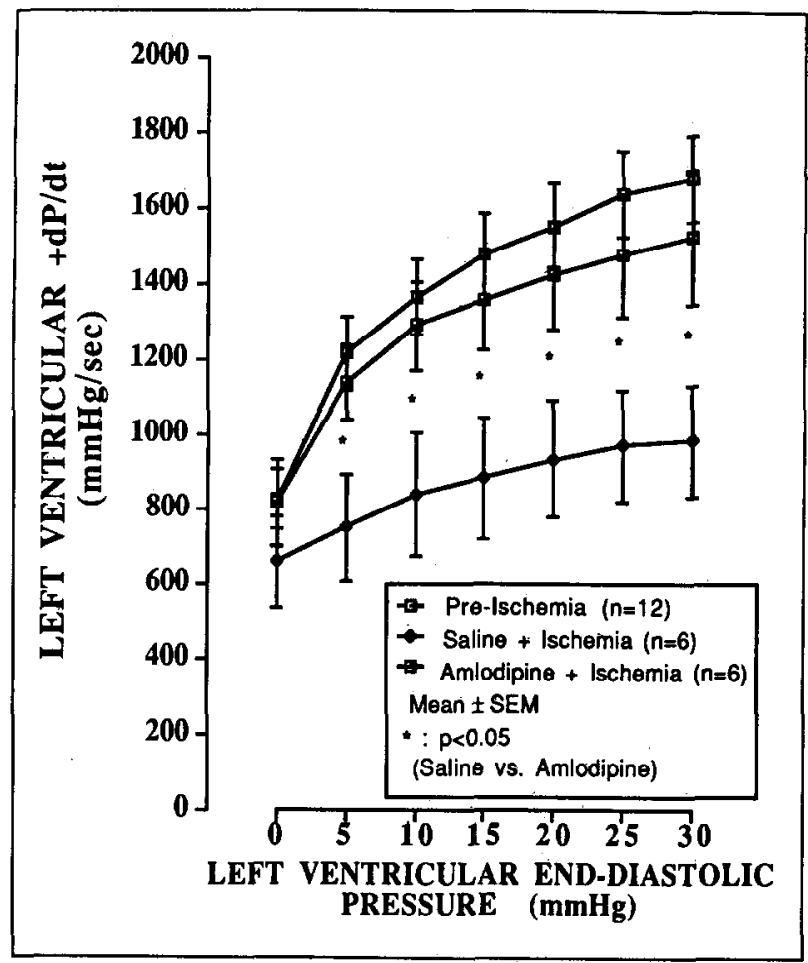

FIGUFi: 8. Lefl vemtricaler +dP/dt of the felline blood-perhused, holited heert. Sail = standard error of the mean.

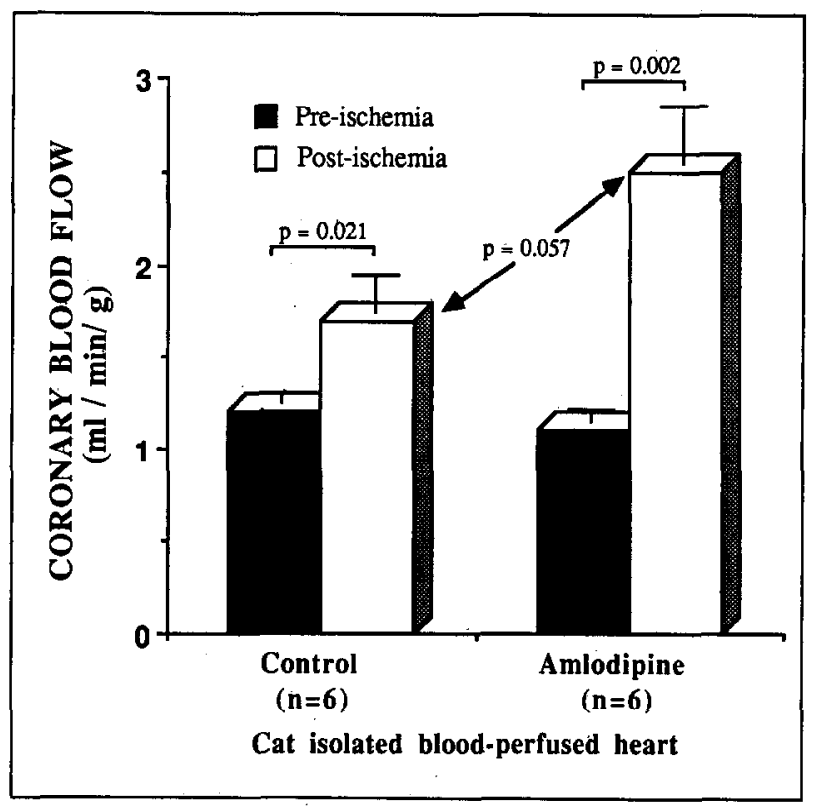

FICURE 9. Coronary blood flow before and after 60 minutes of bechemia phus reperfusion.

pine- and 14 saline-treated dogs) were used in this series of experiments. Four dogs ( 2 amlodipine- and 2 salinetreated dogs) were excluded before the initiation of amlodipine or saline infusion because of failure to manifest any objective evidence of regional myocardial ischemia on left circumflex coronary artery occlusion. Two dogs (1 amlodipine- and 1 saline-treated dog) were excluded because more than 3 attempts at cardioversion were required to reverse ventricular fibrillation. One dog (saline- 


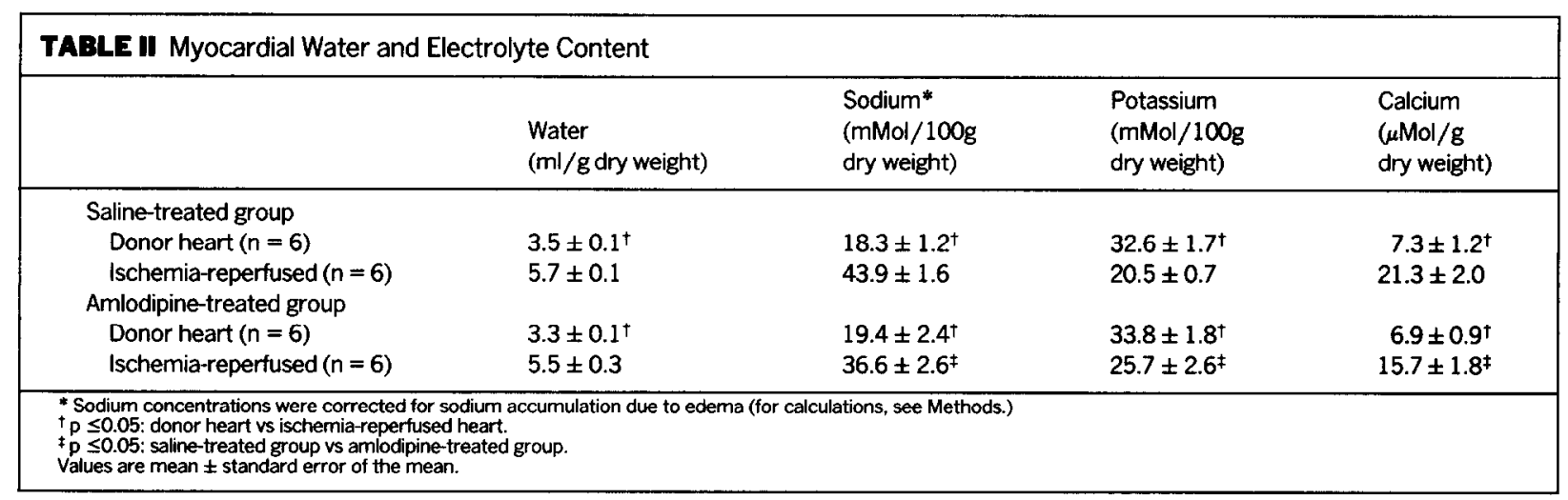

treated) died of intractable ventricular fibrillation during reperfusion and was not included in the final analysis of the data with respect to infarct size. Thus, the final groups consisted of 10 amlodipine- and 10 saline-treated dogs.

Group characteristics: Body weight: Comparison of the 2 groups of animals with respect to body weight failed to demonstrate a significant difference between the 2 groups ( $15.7 \pm 0.3$ vs $16.1 \pm 0.4 \mathrm{~kg}$ for saline vs amlodipine groups).

Heart size: Total heart weight was the same for both groups (136.3 \pm 6.6 vs $140.2 \pm 6.8 \mathrm{~g}$ for saline vs amlodipine groups). Total left ventricular weight was similar in both groups $(94.9 \pm 5.8$ vs $101.6 \pm 4.1 \mathrm{~g}$ for saline vs amlodipine groups).

Area at risk: The area at risk (determined with the dual perfusion method using Evans blue and triphenyltetrazolium), expressed as a percent of the left ventricle, did not differ between the 2 groups ( $40.5 \pm 1.8$ vs $40.2 \pm$ $1.3 \%$ for saline vs amlodipine groups). Overall area at risk for 20 experimental dogs was $40.2 \pm 4.9 \%$ of the total left ventricle. Because the small variability in the size of the risk region, the dependence of infarct size on the area at risk size was eliminated as a variable, therefore making it possible to assess the potential of a pharmacologic agent to reduce ultimate infarct size.
Effect of amlodiplne on uttimate myocardial infarct size: Infarct size analysis is presented in Figure 10. Infarct size expressed as a percent of the anatomic area at risk in the amlodipine-treated group was smaller than that in the saline-treated group $(45.9 \pm 2.8$ vs $34.5 \pm$ $3.8 \%$ for saline vs amlodipine groups; $p \leq 0.025$ ). There was a significant difference in infarct size when the data are expressed as a percent of the left ventricle $(18.6 \pm 1.5$ vs $13.6 \pm 1.6 \%$ for saline vs amlodipine groups; $p<0.05$ ). The ratio of the area at risk of becoming infarcted compared with the area of the left ventricle did not differ between groups ( $40.5 \pm 1.8 \%$ vs $40.2 \pm 1.3 \%$ for saline vs amlodipine). Assessment of infarct size as a percentage of the area at risk demonstrated that treatment with amlodipine produced a $24.8 \%$ reduction in ultimate infarct size.

Hemodynamic parameters: Preocclusion values of heart rate, mean arterial blood pressure, rate-pressure product and mean left circumflex coronary blood flow were similar in the 2 groups (Table III). There were no significant intergroup differences in these parameters during 90 minutes of coronary artery occlusion and 6 hours of reperfusion. Mean arterial blood pressure 30 minutes after reperfusion significantly decreased compared with preischemic control values in the amlodipinetreated group. Mean coronary blood flow between 3 and 6 hours after reperfusion in the saline-treated group was

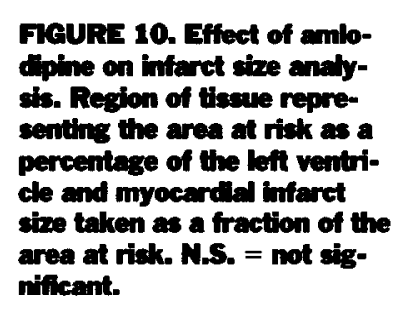

FGURE 10. Effect of ambcipie on intarct cire anajy senting the area at riak as a percentage of the lefit ventricle and myocandild infarct area at rick. N.S. = not significant.

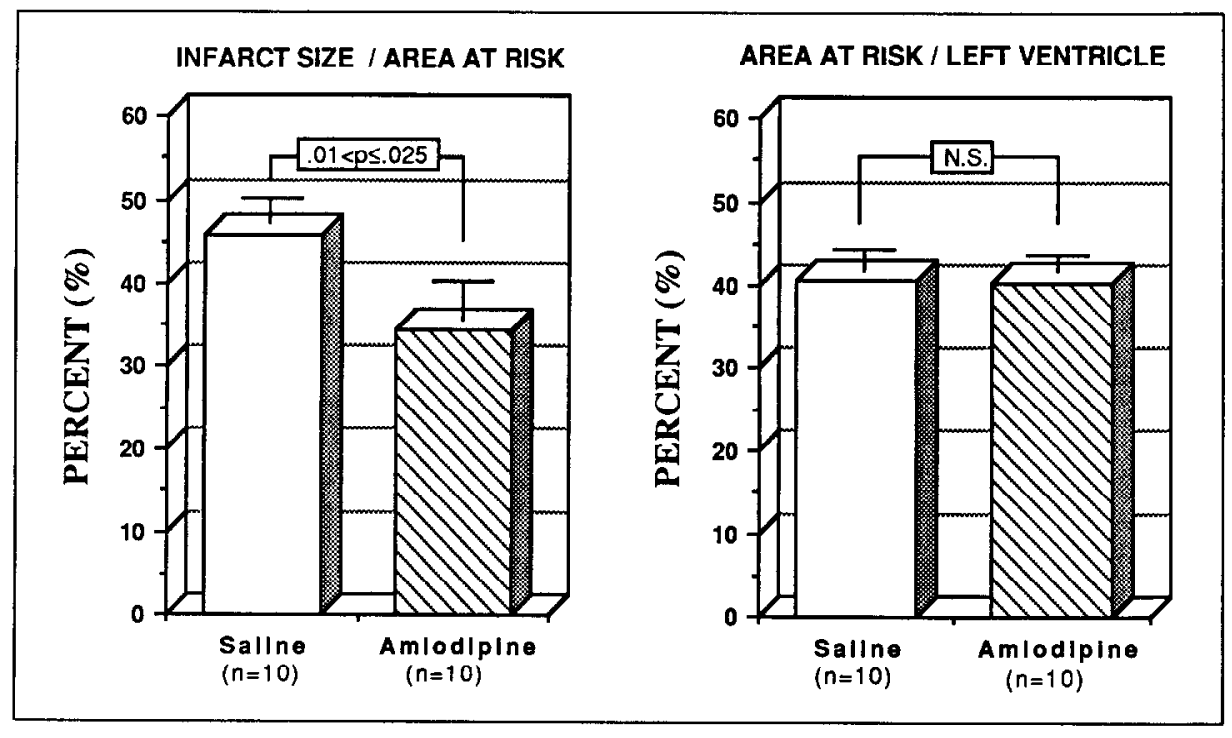

THE AMERICAN JOURNAL OF CARDIOLOGY NOVEMBER 7, 1989 


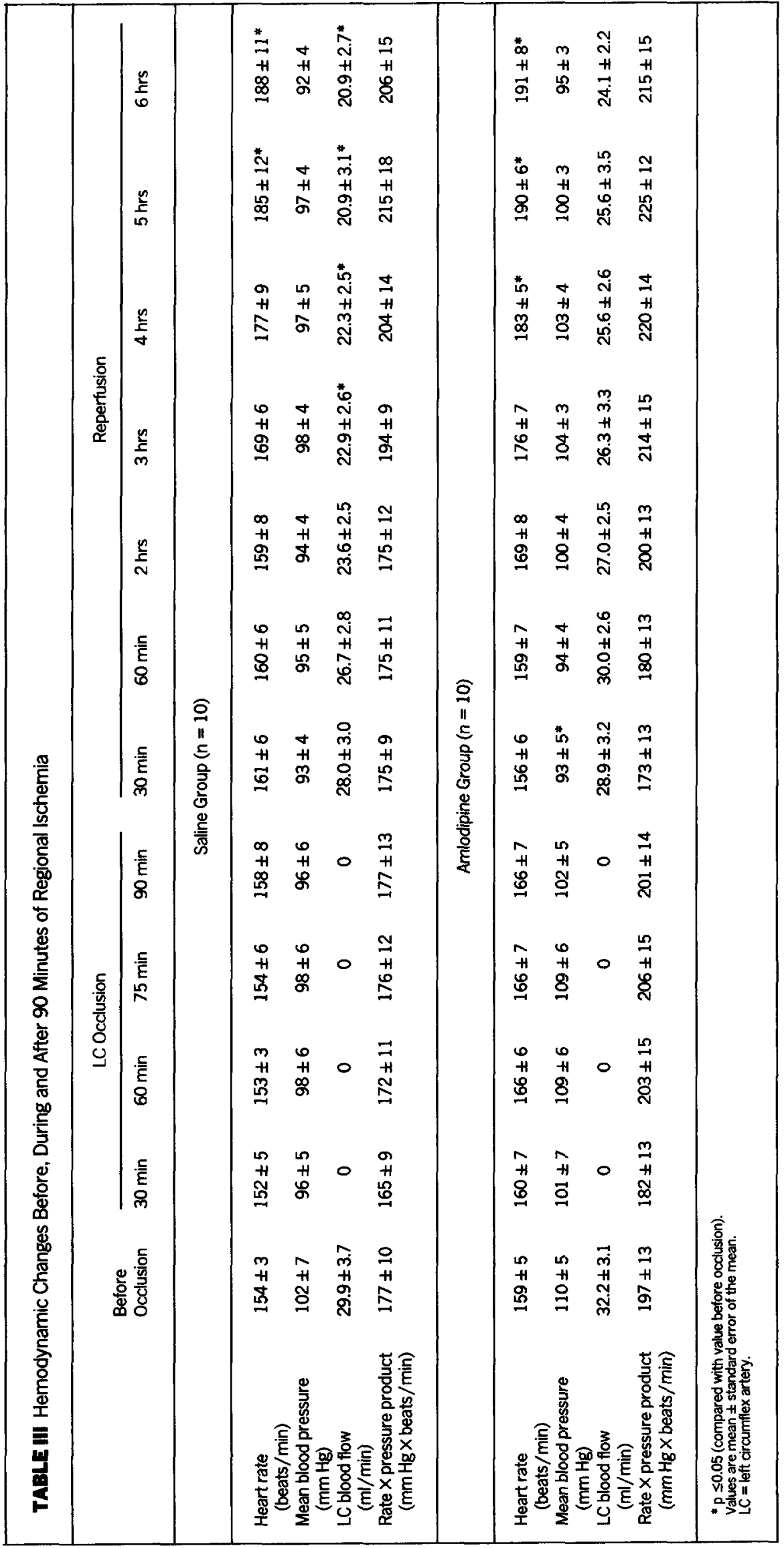




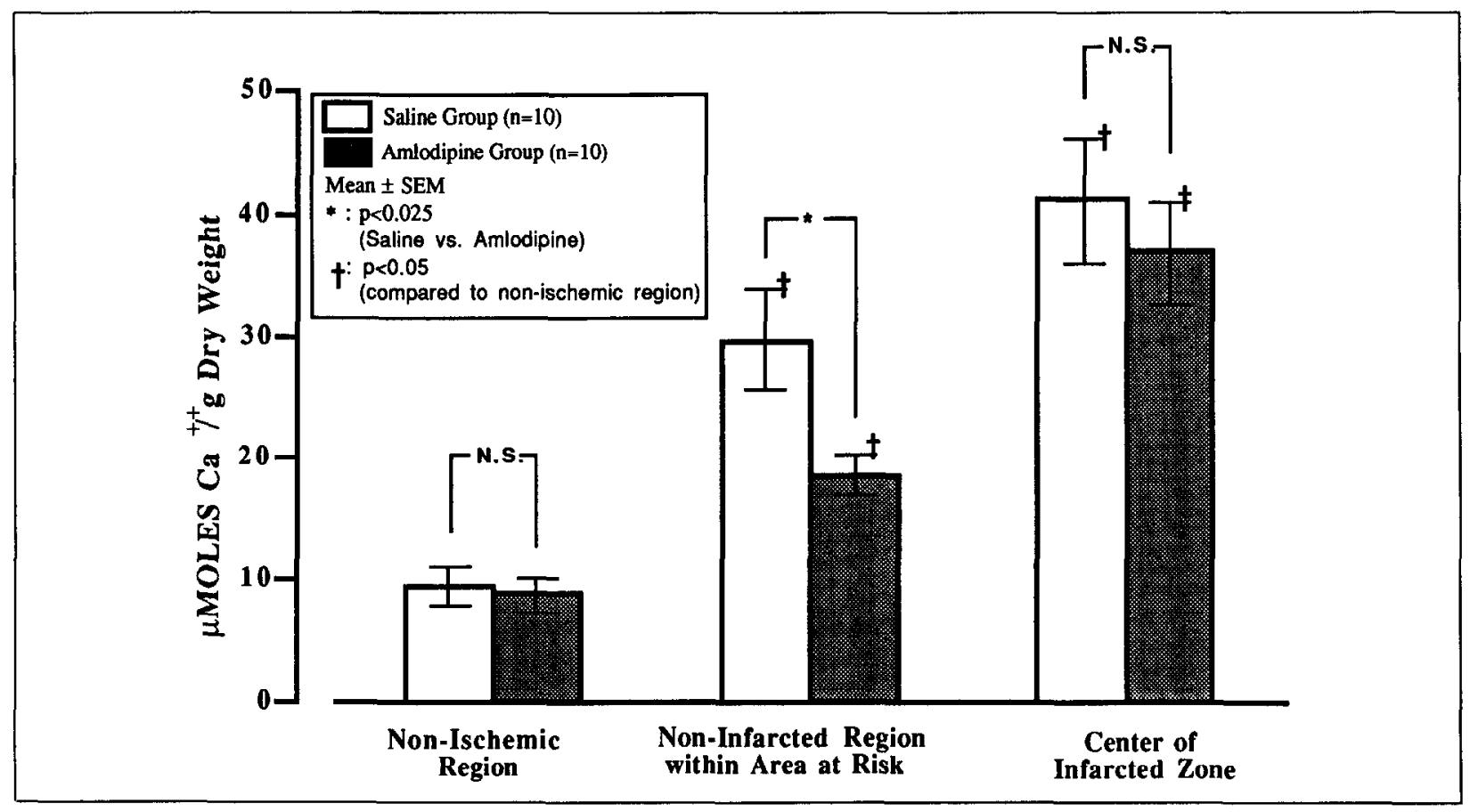

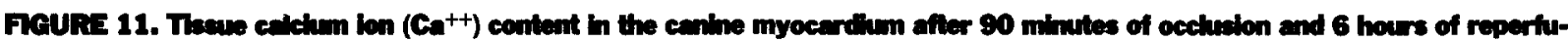
slon. N.S. = not stenificant; SIM = standard error of the moan.

lower than the preischemic values. Heart rate between 5 and 6 hours after reperfusion in the saline-treated group and between 4 and 6 hours after reperfusion in the amlodipine-treated group was increased compared with preischemic control values in each group. However, there were no significant between-group differences over the time course of the protocol. In addition, there were no significant intergroup differences in rate-pressure product after the infusion of saline or amlodipine.

Tiseve calcium content: The $\mathrm{Ca}^{2+}$ content of myocardial tissues is presented in Figure 11. In both groups, the $\mathrm{Ca}^{2+}$ content of noninfarcted and infarcted tissue within the area at risk, was greater than myocardial tissue obtained from the nonischemic region, the content being greater in the central infarcted zone. Amlodipine significantly attenuated the elevation of tissue $\mathrm{Ca}^{2+}$ in the noninfarcted myocardium within the area at risk. Tissue $\mathrm{Ca}^{2+}$ content in the infarcted zone tended to be lower in the amlodipine-treated group, but the difference was not statistically significant.

\section{Discussion}

The experimental results indicate that administration of the new dihydropyridine derivative amlodipine before the onset of global ischemia is effective in preserving myocardial function in the isolated, blood-perfused feline heart. Investigators using diltiazem, ${ }^{30}$ nifedipine ${ }^{31}$ and verapamil ${ }^{32}$ have shown that these agents offer protection in similar settings of myocardial injury. Similarly, amlodipine was shown to decrease the extent of myocardial necrosis when given 15 minutes before reperfusion in the intact canine heart which was subjected to 90 minutes of regional ischemia. Administration of $\mathrm{Ca}^{2+}$ channel entry blockers before the onset of ischemia has been shown to reduce infarct size in models of permanent occlusion and ischemia followed by reperfusion., $8,17,19$ To better understand the role of $\mathrm{Ca}^{2+}$ channel blockade in preventing, rather than delaying, irreversible injury during reperfusion, we gave amlodipine before the onset of reperfusion. The observed reduction in infarct size may be attributable, in part, to the prolonged duration of action of this agent. $^{5}$

The importance of ischemia and reperfusion in the etiology of myocardial cell injury has been reviewed extensively..$^{33,34}$ Corresponding with the onset of ischemia is an abrupt cessation of oxidative phosphorylation in the mitochondria due to the decreased $\mathrm{O}_{2}$ tension. Anaerobic glycolysis is accelerated initially, but eventually declines despite the persistence of endogenous glycogen stores. ${ }^{35}$ As the ischemic interval lengthens, all pathways for the generation of ATP are inhibited, leading to very low concentrations of intracellular ATP. ${ }^{36}$ Because many of the homeostatic mechanisms are energy dependent, regulation of tissue electrolyte composition is abnormal in this setting. Early studies performed in the dog demonstrate that during ischemia, total cellular $\mathrm{Ca}^{2+}$ concentration does not change, ${ }^{37}$ but on the reintroduction of calcium containing perfusion medium, intracellular $\mathrm{Ca}^{2+}$ increases significantly. The increase in intracellular $\mathrm{Ca}^{2+}$ during reperfusion is due to an increase in $\mathrm{Ca}^{2+}$ influx. ${ }^{38}$ The reactivation of oxidative phosphorylation, known to occur during reperfusion, may be involved in the active uptake of $\mathrm{Ca}^{2+} .{ }^{39}$ Steenbergen et $\mathrm{al}^{40}$ showed that intracellular free $\mathrm{Ca}^{2+}$ also increases during ischemia, although at a slower rate, presumably through the release of intracellular $\mathrm{Ca}^{2+}$ stores. The observed changes in $\mathrm{Ca}^{2+}$ and its regulation are thought to be involved in the cellular damage observed in ischemia and reperfusion. 
In this study, we use 2 different experimental models in order to assess the possible therapeutic role of amlodipine in the setting of acute myocardial ischemia and reperfusion. Because of the intrinsic nature of $\mathrm{Ca}^{2+}$ channel entry blockers to relax vascular smooth muscle, the isolated, blood-perfused feline hearts were chosen in order to eliminate the possibility of modified cardiac performance, which might have occurred as a result of decreased afterload or variations in regional myocardial blood flow, or both. One of the particular advantages offered by this model is the absolute assurance of global ischemia. Other investigations using various $\mathrm{Ca}^{2+}$ channel entry blockers and other vasodilators have often referred to "coronary steal" as a possible mechanism, which may account for a possible deleterious effect of these agents. ${ }^{41}$ This phenomenon, however, cannot exist in tissues that are made globally ischemic. In addition to the exclusion of hemodynamic variability, the isolated heart offers the advantage of procuring measurements independent of alterations in central nervous system input to the heart. Previous studies have used this model ${ }^{20,30}$ of global ischemia (60 to 90 minutes) followed by reperfusion (1 to 2 hours) for the assessment of contractile function, electrophysiologic parameters and coronary vascular resistance. We used the isolated heart model as part of a rational protocol designed to assess the effects of amlodipine on myocardial performance and electrolyte balance in the absence of hemodynamic and central nervous system variations.

The susceptibility of the canine heart to myocardial ischemia has been compared with other species, and it has been shown that reproducible regional myocardial necrosis can be achieved after temporary coronary occlusion followed by reperfusion. ${ }^{17,21,22}$ The intact canine heart, unlike the isolated heart protocol, assesses drug responses in an intact physiologic system in which hemodynamic and central nervous system responses are not maintained under artifical control. As a result, drug-related changes in systemic arterial blood pressure, heart rate, coronary blood flow and $\mathrm{MVO}_{2}$ can be monitored. The intact canine heart was used to assess the efficacy of amlodipine in reducing that component of myocardial necrosis, which can be attributed to the late stage of ischemia and reperfusion when the drug is administered 15 minutes before the restoration of regional myocardial perfusion.

Results from isolated, blood-perfused feline hearts: Amlodipine evoked hemodynamic alterations typical of the dihydropyridine class of $\mathrm{Ca}^{2+}$ channel entry blockers in the setting of global ischemia and reperfusion. Amlodipine given before the onset of ischemia increased coronary blood flow in the isolated heart and decreased mean arterial blood pressure in the blood donor cat. The observed actions of amlodipine may be due to the inhibition of the slow inward $\mathrm{Ca}^{2+}$ current. The dihydropyridines are considered to function by binding to specific sites directly within the ion channel. ${ }^{42}$ The binding selectivity of the dihydropyridines may confer an undetermined action independent of ion flux ${ }^{43}$ During ischemia there is a gradual increase in $\left[\mathrm{Ca}^{2+}\right]_{i}$ that is thought to be secondary to the metabolic breakdown of energy-producing systems leading to an inhibition of the ATP-dependent homeostatic control mechanisms. ${ }^{44}$ Pretreating isolated hearts with calcium channel entry blockers has demonstrated a mechanical and biochemical protection during prolonged ischemia. ${ }^{45-47}$

However, experiments performed on isolated myocytes pretreated with specific and nonspecific calcium channel entry blockers (nifedipine and diltiazem; lidoflazine and flunarizine, respectively) failed to prevent hypercontracture with nifedipine and diltiazem, but did protect in the presence of the nonspecific agents lidoflazine and flunarizine. ${ }^{48}$ These results indicate a possible intracellular action of $\mathrm{Ca}^{2+}$ regulation. Recently, Sperelakis et a ${ }^{49}$ suggested that the increase in $\left[\mathrm{Ca}^{2+}\right]_{\mathrm{i}}$ during ischemia may be due to a failure of the metabolic processes to pump free $\mathrm{Ca}^{2+}$ out of the cell. Similarly, Dhalla et al ${ }^{50}$ showed an inhibition of sarcoplasmic reticular $\mathrm{Ca}^{2+}$ ATPase uptake and $\mathrm{Na}^{+} / \mathrm{Ca}^{2+}$ exchange mechanisms during anoxia and ischemia. Because $\mathrm{Ca}^{2+}$ probably enters by more than 1 route during reperfusion, specific $\mathrm{Ca}^{2+}$ channel entry blockers, while effective during ischemia, can only delay but not abolish the reperfusioninduced gain in $\mathrm{Ca}^{2+}$ that is associated with cell death.

Tissue electrolyte analysis showed that amlodipine was able to inhibit the changes in myocardial electrolyte concentrations due to ischemia/reperfusion. Global ischemia followed by reperfusion was associated with an increase in myocardial $\mathrm{Ca}^{2+}$ and $\mathrm{Na}^{+}$, and a loss in tissue $\mathrm{K}^{+}$. These results are consistent with previous studies that describe alterations in electrolyte homeostasis during ischemia/reperfusion ${ }^{37,51}$ In comparison with control hearts, amlodipine pretreatment substantially reduced the relative increase in $\left[\mathrm{Ca}^{2+}\right]_{i}$ and $\left[\mathrm{Na}^{+}\right]_{i}$, and reduced the loss of $\left[\mathrm{K}^{+}\right]_{\mathrm{i}}$ associated with ischemia. Because the samples were obtained after 1 hour of reperfusion, $\mathrm{Ca}^{2+}$ measurements do not reflect changes in $\left[\mathrm{Ca}^{2+}\right]_{\mathrm{i}}$ resulting from ischemia. During prolonged ischemia (>20 minutes) $\left[\mathrm{Ca}^{2+}\right]_{\mathrm{i}}$ increased, but total cellular $\mathrm{Ca}^{2+}$ remained constant; this subtlety reflects intracellular functional derangements in the mitochondria and sarcoplasmic reticulum. Nayler et $a^{52}$ performed ultrastructural analysis of the sarcolemmal membrane after 60 minutes of ischemia and found it to be largely intact. The observed increase in $\left[\mathrm{Ca}^{2+}\right]_{i}$ in our experimental model is consistent with the rapid influx of $\mathrm{Ca}^{2+}$ that occurs on reperfusion. Reperfusion-associated increases in $\left[\mathrm{Ca}^{2+}\right]_{i}$ cannot occur through activation of the slow channels alone..$^{52}$ It has been postulated that the gradual loss of membrane integrity occurs during ischemia by various mechanisms including: activation of phospholipases, ${ }^{53}$ accumulation of lipids, ${ }^{54} \mathrm{O}_{2-}$ free radicals ${ }^{55}$ or other undefined mechanisms, thus removing the physical barriers allowing the free diffusion of $\mathrm{Ca}^{2+}$ down its concentration gradient that occurs at reperfusion. Therefore, the relative decrease in total $\left[\mathrm{Ca}^{2+}\right]_{i}$ after amlodipine pretreatment may be due to an inhibitory action on those events that lead to the initiation of membrane damage during the ischemic period; the metabolic and structural alterations that normally serve as the substrate for reperfusion injury- $\mathrm{Ca}^{2+}$ overloadare eliminated. By pretreating the globally ischemic/re- 
perfused heart, we did not define the role of the $\mathrm{Ca}^{2+}$ channel blockers in reperfusion injury.

During ischemia there was a rapid decline in developed tension and a progressive increase in LVEDP beginning between 10 and 20 minutes after cessation of flow. Although we did not obtain tissue $\mathrm{Ca}^{2+}$ measurements throughout the ischemic interval, the progressive increase in LVEDP has previously been shown to be associated with a steady increase in free $\left[\mathrm{Ca}^{2+}\right]_{\mathrm{i}}{ }^{56}$ The increased $\left[\mathrm{Ca}^{2+}\right]_{\mathrm{j}}$ may be due to an inability of myocytes to remove free $\mathrm{Ca}^{2+}$ from the cytoplasmic space through an inhibition of the active reuptake systems of the sarcoplasmic reticulum, mitochondria, and sarcolemmal membrane ${ }^{49}$ Previous studies have shown that the increase of $\left[\mathrm{Ca}^{2+}\right]_{i}$ that occurs during anoxia and ischemia is not due to an influx of extracellular $\mathrm{Ca}^{2+}$, but is related to alterations in $\mathrm{Ca}^{2+}$ extrusion and sequestration. ${ }^{50,56}$ The redistribution of $\left[\mathrm{Ca}^{2+}\right]_{\mathrm{i}}$ into usable free $\mathrm{Ca}^{2+}$ inhibits mitochondrial oxidative phosphorylation by diverting energy production to the active sequestration of $\mathrm{Ca}^{2+}$ in the mitochondria. ${ }^{50}$ Amlodipine inhibited the increase in LVEDP throughout the 60-minute period of ischemia. By inhibiting the onset of myocyte hypercontracture, amlodipine may prevent the further mechanical disruption and chemical degradation of an already compromised sarcolemmal membrane, thereby making the cells less susceptible to $\mathrm{Ca}^{2+}$ overload on reperfusion. This action of amlodipine and the other calcium channel entry blockers, when given before the onset of ischemia, is similar to the energy-sparing drugs ${ }^{57}$ and high-energy phosphate precursors. ${ }^{58,59}$ Amlodipine, in addition to its action on the slow calcium channel, may function by a mechanism, as yet to be described, involving the intracellular regulation of $\mathrm{Ca}^{2+}$ release from the sarcoplasmic reticulum.

Two indexes of myocardial function were used to assess the physiologic effects of amlodipine (compliance and function). Amlodipine improved functional recovery on reperfusion, but did not afford a complete return to baseline conditions. These results suggest that amlodipine exerts a protective effect during ischemia/anoxia, but on reperfusion, a degree of protection is lost. Reperfusion injury is a complex and multifactorial event. ${ }^{33,44}$ The common final denominator, however, appears to be the rapid influx of $\mathrm{Ca}^{2+}$ concomitant with the reintroduction of molecular $\mathrm{O}_{2}$ and metabolic substrates. The "calcium paradox" or calcium overload can occur even in the absence of $\mathrm{O}_{2}$; intracellular accumulation of $\mathrm{O}_{2}$ radicals during ischemia may be sufficient to cause cell damage, thus allowing for rapid $\mathrm{Ca}^{2+}$ influx. ${ }^{52,55}$ Calcium can enter the damaged myocyte through a variety of different pathways including $\mathrm{Na}^{+}-\mathrm{Ca}^{2+}$ exchange, diffusion through damaged membrane, ion-channels and release from intracellular stores. It has been shown that amlodipine and the related dihydropyridines can prevent $\mathrm{Ca}^{2+}$ influx through the ion channel. Other pathways for $\mathrm{Ca}^{2+}$ entry undoubtedly remain functional, thus preventing full recovery of function despite previous administration of amlodipine..$^{52}$ Closely related to the recovery of contractile function is the fact that amlodipine reduced $\mathrm{MVO}_{2}$ (arteriovenous difference). Coronary blood flow was im- proved, an event that may have been due to a direct action on the vascular smooth muscle. Alternatively, because coronary blood flow is impeded by extravascular compression, prevention or reduction in the development of contracture during ischemia and especially on reperfusion would result in an improved distribution of blood flow to the myocardium, which would not necessarily be reflected in an overall increase in total coronary blood flow. Furthermore, the no-reflow phenomenon may have been prevented by amlodipine, thus facilitating better perfusion of the tissue on the restoration of coronary flow. Our experimental design did not enable us to differentiate whether improved performance was due to decreased $\mathrm{MVO}_{2}$ or an improved tissue distribution of coronary flow.

Results from intact canine hearts: Previous studies have shown that $\mathrm{Ca}^{2+}$ channel entry blockers are effective in reducing infarct size and improving cardiac function when administered before the onset of coronary artery occlusion in intact animal preparations. ${ }^{17,60}$ Possible cardioprotective mechanisms have been described and include increased regional myocardial blood flow, decreased afterload through systemic arteriolar dilation, decreased $\mathrm{MVO}_{2}$, decreased heart rate and direct negative inotropic effects. Direct inhibition of neutrophil activation may also play a beneficial role in reducing the ultimate extent of damage. ${ }^{61,62}$ In contrast, calcium channel entry blockers are ineffective when administered concomitantly with reperfusion. ${ }^{43}$ Intervention with low $\mathrm{Ca}^{2+}$ containing solutions or acidic reperfusate can delay, but not prevent, the expression of cellular damage. ${ }^{52}$

Convincing evidence has shown that much of the damage associated with reperfusion occurs within minutes of the restoration of flow ${ }^{25}$ Shen and Jennings ${ }^{37}$ showed that total cellular $\mathrm{Ca}^{2+}$ was unchanged during ischemia, but increased abruptly on reperfusion. The failure of calcium channel entry blockers to improve cardiac function and reduce infarct size when given during reperfusion alone is likely due to the rapid loss of sarcolemmal membrane integrity associated with restoration of flow and subsequent loss of homeostatic mechanisms. Ischemia primes the cells for destruction through activation of proteases, $\mathrm{O}_{2}$-free radicals and calcium ATPases. ${ }^{13,50}$ Gross disruption of the sarcolemma develops in association with reperfusion and such perturbations are not evident during ischemia alone, despite the fact that the cell membrane has been altered with respect to its permeability characteristics. $52,63,64 \mathrm{As}$ a result, $\mathrm{Ca}^{2+}$ moves unimpeded into the cytoplasmic space during reperfusion. $\mathrm{Ca}^{2+}$ influx may be one of the final common pathways that result in myocardial dysfunction and necrosis.

In deference to its relatively prolonged onset of action, we administered amlodipine 15 minutes before the onset of reperfusion. In contrast to other studies in which $\mathrm{Ca}^{2+}$ antagonists given at the time of reperfusion demonstrated no reduction in infarct size or improvement in myocardial function, ${ }^{38,43,65}$ amlodipine reduced infarct size and decreased intracellular $\mathrm{Ca}^{2+}$ concentrations in the noninfarcted tissue in the area at risk. In a study performed with the working rat heart, Higgins et $a l^{43}$ observed no 
protective effect by verapamil or diltiazem when the drugs were administered at the time of reperfusion; nifedipine and the calmodulin antagonist W-7, however, were found to be beneficial when given at reperfusion or when given before ischemia. They concluded that $\mathrm{Ca}^{2+}$ antagonists may act differentially on the sarcolemmal membrane. Furthermore, it was suggested that nifedipine may exert its protective effects by an intracellular action similar to that attributed to W-7 on calmodulin. ${ }^{66}$

Our data suggest that the observed reduction in myocardial infarct size was independent of altered hemodynamic parameters: heart rate, mean arterial blood pressure, coronary blood flow and the rate-pressure product that did not differ between treated and control animals. The possibility remains, however, that alterations in regional myocardial blood flow may have contributed to tissue salvage. Studies done in a canine model of severe ischemic injury showed that nifedipine reduced myocardial injury due to an increase in collateral blood flow. ${ }^{8}$ Pretreatment with amlodipine 15 minutes before reperfusion may have attenuated late ischemic phase alterations in the homeostatic mechanisms. Nayler et al ${ }^{67}$ showed that the duration of ischemia is directly proportional to a decrease in dihydropyridine receptor affinity $\left(\mathbf{k}_{d}\right)$ and receptor density $\left(B_{\max }\right)$ for the low affinity slow calcium channel, thereby allowing increased binding of nifedipine during ischemia; such alterations have not been demonstrated during reperfusion. This increased binding may be associated with an increase in membrane stability. Data from Jennings et al ${ }^{59}$ and Poole-Wilson et a ${ }^{65}$ suggest that $\mathrm{Ca}^{2+}$ antagonists may increase sarcolemmal membrane stability. By increasing membrane stability during ischemia, amlodipine may preserve the integrity of intracellular $\mathrm{Ca}^{2+}$ homeostatic mechanisms throughout reperfusion, allowing better extrusion of $\mathrm{Ca}^{2+}$ through the energy-dependent pumps, thereby attenuating $\mathrm{Ca}^{2+}$ overload and the resultant myocardial damage. Dhalla et $a^{50}$ suggested that irreversible damage occurs on reperfusion when $\mathrm{Ca}^{2+}$ removal becomes defective. Our results indicate that amlodipine, although it did not completely inhibit the increase in $\left[\mathrm{Ca}^{2+}\right]_{i}$ in the noninfarcted tissue, it did attenuate the increase in myocardial $\left[\mathrm{Ca}^{2+}\right]_{\mathrm{i}}$ compared with controls.

It has become recognized that the excessive influx of $\mathrm{Ca}^{2+}$ associated with ischemia/reperfusion injury occurs almost exclusively during reperfusion; this increase cannot be due to increased conductance through the $\mathrm{Ca}^{2+}$ channel alone. ${ }^{38,43}$ By administering amlodipine 15 minutes before reperfusion, we have demonstrated a reduction of infarct size that has been typical of hearts treated before ischemia, but unlike those treated only during reperfusion. These results cannot be attributed to alterations in hemodynamic parameters. Although not determined in the present study, the observed beneficial effect of amlodipine may have occurred as a result of improved distribution in regional blood flow to the reperfused myocardium. Prophylactic treatment with amlodipine during late ischemia may provide enough protection to keep the sarcolemma and tissue calcium homeostatic mechanisms intact during reperfusion. Relative reductions in the accumulation of $\left[\mathrm{Ca}^{2+}\right]_{i}$ compared with control suggest that amlodipine may exert a direct protective effect on the myocardium during ischemia, which may carry over into the reperfusion phase through membrane stabilization or, as suggested earlier, through an intracellular mechanism. Amlodipine may also reduce activation of leukocytes that would limit enzymatic and oxidative damage associated with ischemia and reperfusion in particular. ${ }^{61,62}$

\section{CONCLUSION}

The data suggest that the long-acting dihydropyridine derivative amlodipine is effective in preserving myocardial contractile function and reducing the extent of $\mathrm{Ca}^{2+}$ accumulation after 60 minutes of ischemia and reperfusion when administered before the onset of ischemia in an isolated, blood-perfused feline heart. We also demonstrated that amlodipine, given 15 minutes before the onset of reperfusion after 75 minutes of regional ischemia, limits ultimate infarct size in the canine heart subjected to 90 minutes of ischemia and 6 hours of reperfusion. The observed protective effect was associated with a reduction in tissue $\mathrm{Ca}^{2+}$ accumulation in the noninfarcted region of the area at risk. Amlodipine may be useful as a cardioprotective agent providing preservation of cardiac function and cell viability during events that involve myocardial ischemia and reperfusion.

\section{REFERENCES}

1. Stone PH, Antman EM, Muller JE, Braunwald E. Calcium channel blocking agents in the treatment of cardiovascular disorders. Part II. Hemodynamic effects and clinical applications. Ann Intern Med 1980,93:886-904.

2. Ellrodt G, Chew CYC, Singh BN. Therapeutic implications of slow-channel blockade in cardiocirculatory disorders. Circulation 1980,62:669-679.

3. Reid JL. Pharmacokinetics of $\mathrm{Ca}^{2+}$ antagonists. $J$ Cardiovasc Pharmacol 1988:12:suppl 7:522-526.

4. Echizen H, Vogelsang B, Eichelbaum M. Effects of d,l-verapamil, nifedipine, and diltiazem. Clin Pharmacol Ther 1986:2:425-449.

5. Burges RA, Carter AJ, Gardiner DG. Higgens AJ. Amlodipine, a new dihydropyridine calcium blocker with slow onset and long duration of action (abstr). Br $J$ Pharmacol 1985;85:281P.

6. Singh BN. The mechanism of action of $\mathrm{Ca}^{2+}$ antagonists relative to their application. Br J Clin Pharmacol 1986;21:suppl 2:109-225.

7. Triggle DJ, Swamy VC. Pharmacology of agents that affect calcium: agonists and antagonists (abstr). Chest 1980;78:174.

8. Henry PD, Schuchlib R, Borda CJ, Roberts R, Williamson JR, Sobel BE. Effects of nifedipine on myocardial perfusion and ischemic injury in dogs. Circ Res 1978:43:372-380.

9. Nayler WG, Ferrari R, Williams A. Protective effect of pretreatment with verapamil, nifedipine, and propranolol on mitochondrial function in the ischemic and reperfused myocardium. Am J Cardiol 1980;46:242-248.

10. Perez PE, Sobel BE, Henry PD. Improved performance of ischemic canine myocardium in response to nifedipine and diltiazem. Am J Physiol 1980;239: H658-H663.

11. Trump BF, Mergner WJ, Kahang MW, Saladino AJ. Studies on the subcellular pathophysiology of ischemia. Circulation 1976;53:suppl 1:1-117-I-126.

12. Katz AM, Reuter H. Cellular calcium and cardiac cell death. Am J Cardiol 1979;44:188-190.

13. Buja LM, Hagler HK, Willerson JT. Altered calcium homeostasis in the pathogenesis of myocardial ischemic and hypoxic injury. Cell Calcium 1988,9: 205-217.

14. Reimer KA, Jennings RB. Myocardial ischemia, hypoxia, and infarction. In: Fozzard HA, Haber E, Jennings RB, Katz AM, Morgan HE, eds. The Heart and Cardiovascular System. New York: Raven Press, 1986;1133-1201.

15. Buja LM. Basic pathological processes of the heart: relationship to cardiomyopathies. In: Sperelakis N, ed. Physiology and Pathophysiology of the Heart. Boston: Marinus Nijhoff, 1984,43-57.

16. Hagler HK, Burton KP, Buja LM. Electron probe $x$-ray microanalysis of normal and injured myocardium: methods and results. In: Hutchinson TE, Som- 
lyo AP, eds. Microprobe Analysis of Biological Systems. New York: Academic Press, 1981:122-155.

17. Bush LR, Romson JL, \sh JL, Lucchesi BR. Effects of diltiazem on extent of ultimate myocardial injury resulting from temporary coronary artery occlusion in dogs. J Cardiovasc Pharmacol 1982;4:285-296.

18. Tumas J, Deth R, Kloner RA. Effects of nisoldipine, a new calcium antagonist, on myocardial infarct size and cardiac dynamics following acute myocardial infarction. J Cardiovasc Pharmacol 1985:7:361-367.

19. Selwyn AP, Welman E, Fox K, Horlock P, Pratt T, Klein M. The effects of nifedipine on acute experimental myocardial ischemia and infarction in dogs. Circ Res 1979;44:16-23.

20. Vogel WM, Lucchesi BR. An isolated blood perfused feline heart preparation for evaluating pharmacological interventions during myocardial ischemia. $J$ Pharmacol Methods 1980;4:291-303.

21. Jolly SR, Kane WJ, Bailie MB, Abrams GD, Lucchesi BR. Canine myocardial reperfusion injury: its reduction by the combined administration of superoxide dismutase and catalase. Circ Res 1984;54:277-285.

22. Werns SW, Shea MJ, Mitsos SE, Dysko RC, Fantone JC, Schork A, Abrams GD, Pitt B, Lucchesi BR. Reduction of the size of infarction by allopurinol in the ischemic reperfused canine heart. Circulation 1986;73:518-524.

23. Katz AM, Tada $M$. The "stone heart" and other challenges to the binchemist. Am J Cardiol 1977;39:1073-1077.

24. Apstein CS, Mueller M, Hood WB. Ventricular contracture of the myocardium: mechanisms and prevention. Am J Cardiol 1977;39:968-993.

25. Hearse DJ. Reperfusion of ischemic myocardium. J Mol Cell Cardiol 1977,9:605-613

26. Nasser FN, Walls JY, Edwards WD. Harrison CD. Lidocaine-induced reduction in size of experimental myocardial infarction. Am I Cardiol 1980 46:975-976

27. Romson JL, Hook BG, Rigot VH, Schork MA, Swanson DP, Lucchesi BR The effect of ibuprofen on the accumulation of indium-iii-labeled platelets and leukocytes in experimental myocardial infarction. Circulation 1982,66:10021011

28. Vivaldi MT, Kloner RA, Schoen FJ. Triphenyltetrazolium staining of irreversible ischemic injury following coronary artery occlusion in rats. Am J Pathol 1985; 121:522-530.

29. Romaschin AD, Rebeyka I, Wilson GJ, Mickle DAG. Conjugated dienes in ischemic myocardium: an in vivo chemical signature of oxygen free radicals mediated injury. J Mol Cell Cardiol 1987:19:289-302.

30. Bush LR, Li Y-P, Shlafer M, Jolly SR, Lucchesi BR. Protective effects of diltiazem during myocardial ischemia in isolated cat hearts. I Pharmacol Exp Ther 1981;218:3.653-661.

31. Weintraub WS, Hattori S, Agarwal JB, Bodenheimer MM, Banka VS Helfant RH. The effects of nifedipine on myocardial blood flow and contraction during ischemia in the dog. Circulation 1982,65:49-53.

32. Nayler WG, Grau A, Slade A. A protective effect of verapamil on hypoxic heart muscle. Cardiovasc Res 1976:106650-662.

33. Hearse DJ, Humphrey SM, Nayler WG, Slade A, Border D. Ultrastructural damage associated with reoxygenation of the anoxic myocardium. $J$ Mol Cell Cardiol 1975,7:315-324.

34. Jennings RB, Steenbergen $C$. Nucleotide metabolism and cellular damage in myocardial ischemia. Annu Review Physiol 1985;47:727-749.

35. Rovetto MJ, Lamberton WF, Neely JR. Mechanisms of glycolytic inhibition in ischemic rat hearts. Circ Res 1975;37:742-751.

36. Bailey IA, Williams SR, Radda GK, Guadian DG. Activity of phosphorylase in total global ischemia in the rat heart. Biochem $\mathrm{J} 1981 ; 196: 171-178$. 37. Shen AC, Jennings RB. Kinetics of calcium accumulation in acute myocardial ischemic injury. Am J Pathol 1972,67:235-243.

38. Bourdillon PD, Poole-Wilson PA. The effects of verapamil, quiescence, and cardioplegia on calcium exchange and mechanical function in ischemic rabbit myocardium. Circ Res 1982;50:360-368.

39. Smith GC, Allen DG. Effects of metabolic blockade on intracellular calcium concentration in isolated ferret ventricular muscle. Circ Res 1988,62:1223-1236. 40. Steenbergen L, Murphy E, Levy E, London RE. Elevation in cytosolic free calcium concentration early in myocardial ischemia in perfused rat heart. Circ Res 1987,60:700-707

41. Schaper $W$, Lewi $P$, Flameng W, Gijpen L. Myocardial steal provided by coronary artery occlusion. Basic Res Cardiol 1973,68:3-20.

42. Ehlert FJ, Roeske WR, Itoga $E$, Yamamura HI. The binding of [3H]nitrendipine to receptors for calcium channel antagonists in the heart, cerebral cortex and ileum of rats. Life Sci 1982;30:2191-2202.

43. Higgins AJ, Blackburn KJ. Prevention of reperfusion damage in working rat hearts by calcium antagonists and calmodulin antagonists. $J$ Mol Cell Cardiol 1984;16:427-438.

44. Braunwald $E$. Mechanism of action of calcium-channel blocking agents. $N$ Engl J Med 1982;307:26:1618-1627

45. Ichihara K, Abiko Y. Effects of diltiazem and propranolol on irreversibility of ischemic cardiac function and metabolism in the isolated perfused rat heart. $J$ Cardiovasc Pharmacol 1983;5:745-751.

46. Nayler WG, Ferrari R, Williams A. Protective effect of pretreatment with verapamil, nifedipine, and propranolol on mitochondrial function in the ischemic and reperfused myocardium. Am $J$ Cardiol 1980:46:242-248.

47. Sugiyama S, Miyazaki Y, Kotaka H, Ozawa T. The effects of verapamil on mitochondrial dysfunction associated with coronary reperfusion. Jpn Circ J 1983;47:830.

48. Borgers M, Ver Donck L, Vanderplassche G. Pathophysiology of cardiomyocytes. Ann NY Acad Sci 1988;522:433-453.

49. Sperelakis N. Regulation of calcium slow channels of cardiac muscle by cyclic nucleotides and phosphorylation. J Mol Cell Cardiol 1988:20:II:75-105.

50. Dhalla NS, Panagia V, Singal PK, Makino N, Dixon IMC, Eyolfson DA. Alterations in heart membrane calcium transport during the development of ischemia-reperfusion injury. $\mathrm{J} \mathrm{Mol}$ Cell Cardiol 1988;20:3-13.

51. Poole-Wilson PA, Tones MA. Sodium exchange during hypoxia and on reoxygenation in the isolated rabbit heart. J Mol Cell Cardiol 1988;20:II:15-22. 52. Nayler WG, Panagiotopoulos S, Elz JS, Daly MJ. Calcium-mediated damage during postischaemic reperfusion. $\mathrm{J}$ Mal Cell Cardiol 1988;20:11:41-54.

53. Weglicki SB, Waite M, Stam AC. Association of phospholipase A with a myocardial membrane preparation containing the $\left(\mathrm{Na}^{++} \mathrm{K}^{+}\right)-\mathrm{Mg}^{2+}$-ATPase. $J$ Mol Cell Cardiol 1972;4:195-201

54. Katz AM, Messineo FC. Lipid-membrane interactions and the pathogenesis of ischemic damage in the myocardium. Circ Res 1981:48:1-16.

55. Ferrari R, Ceconi S, Curello C, Guarnieri CM, Albertini A, Visiolo $O$ Oxygen-mediated myocardial damage during ischemia and reperfusion. Role of the cellular defences against oxygen toxicity. $J$ Mol Cell Cardiol 1985;17:937945 .

56. Bourdillon PD, Poole-Wilson PA. Effects of ischemia and reperfusion on calcium exchange and mechanical function in isolated rabbit myocardium. Cardiovasc Res 1981:15:121-130.

57. Watts JA, Koch CD, La Nove KF. Effects of calcium antagonism on energy metabolism: calcium and heart function after ischemia. Am J Physiol 1980 238:H909-H916.

58. Zimmer HG, Ibel $H$. Ribose accelerated the repletion of the ATP pool during recovery from reversible ischemia of the rat myocardium. $J$ Mol Cell Cardiol 1984:16:863-866.

59. Jennings RB, Schaper J, Hill MC, Steenbergen C, Reimer KA. Effect of reperfusion late in the phase of reversible ischaemic injury: changes in cell volume, electrolytes and ultrastructure. Circ Res 1985;56:262-278.

60. Korn NL, Pollack JV, Spath JA. Effects of intracoronary verapamil administration in a sheep model of acute myocardial ischemia and reperfusion. Circ Res 1988,62:1138-1146.

61. Irita K, Fujita I, Takeshiga K, Minakami S, Yoshitake J. Calcium channel antagonist induced inhibition of superoxide production in human neutrophils. Biochem Pharmacol 1986;35:20:3465-3471.

62. Jouvin-Marche E. Effect of the $\mathrm{Ca}^{2+}$ antagonist nifedipine on the release of platelet-activating factor (PAF-acether), slow-reacting substance, and $\beta$-glucuronidase from human neutrophils. Eur J Pharmacol 1983;89:19-26.

63. Rao PS, Cohen MV, Moeller HS. Production of free radical and lipid peroxidase in early experimental myocardial ischemia. (Rapid communication). $J$ Mol Cell Cardiol 1983;15:713-716.

64. Camilleri JP, Joseph D, Amat D, Fabianai JN. Impaired sarcolemmal membrane permeability in reperfused ischemic myocardium. Virchows Arch 1980;388: $68-76$.

65. Poole-Wilson PA, Harding DP, Bourdillon PDV, Tones MA. Calcium out of control. J Mol Cell Cardiol 1984:16:175-187.

66. Asano M, Suzuki $Y$, Hidaka $H$. Effects of various calmodulin antagonists on contraction of rabbit aortic strips. J Pharmacol Exp Ther 1982;220:1:191-196. 67. Nayler WG, Dillon JS, Sturrock WJ. Dihydropyridines and the protection of the ischaemic and anoxic myocardium. In: Fleckenstein A Van Breemen C Gross R, Hoffmeister F, eds. Bayer-Symposium IX. Cardiovascular Effects of Dihydropyridine-Type Calcium Antagonists and Agonists. Heidelberg: Springer-Verlag, $1985 ; 460-471$

\section{PANEL DISCUSSION}

Dr. Glossmann (Innebruck, Austria): I can try to answer 1 question and this is that you have 1,4-dihydropyridine and diltiazem which do the same thing. I can exclude the mitochondrial site which we work on. We can exclude the nucleotide carrier as a target for both the drugs, and I think we can also exclude the channel. So this leaves us with a fourth site, and I can say this because the verapamil group of drugs always goes together for all the receptors. If you study Escherichia coli or mitochondria, all this goes together with the DHP receptor. We have not found yet, a receptor where the diltiazem-benzodiazepine site goes together with the 1,4-dihydropyridine site. 
Dr. Nayler (Vietoria, Australia): Do you have any information on what is happening to the cytoskeleton of the myocytes in your calcium antagonist treated model?

Dr. Lucchesi (Ann Arbor, Michigan): Yes, I have some very nice electron micrographs on this subject. There appears to be excellent preservation of the ultrastructure.

Dr. Nayler: Not just ultrastructure, but also the cytoskeleton of the cell? tion.

Dr. Lucchesi: No, I don't have that kind of informa-

Dr. Nayler: I think this is terribly important because we must stop the cell membrane from swelling, which means we have to keep it anchored. I wonder if the calcium antagonist drugs have this effect?
Dr. Lucchesi: I can't answer that.

Dr. Nayler: We agree with you the ultrastructure is marvelously preserved, but we are also looking now in detail at the cytoskeleton of the cell.

Dr. Lucchesi: I might point out that I didn't show the data, but in our mitochondrial studies, mitochondrial function is beautifully preserved.

Dr. Vanhoutte (Rochester, Minnesota): The story you tell us today and your story too, Dr. Nayler, reminds me very strongly of the stories on lidoflazine about 10 years ago. Does that help in understanding why those drugs could act and what they could do?

Dr. Lucchesi: I think lidoflazine is acting very much in the same way. 